\title{
Picornavirus IRES elements: RNA structure and host protein interactions
}

\author{
Encarnación Martínez-Salas*, Rosario Francisco-Velilla, Javier Fernandez-Chamorro, \\ Gloria Lozano, Rosa Diaz-Toledano
}

Centro de Biología Molecular Severo Ochoa, Consejo Superior de Investigaciones Científicas - Universidad Autónoma de Madrid, Nicolas Cabrera 1, 28049 Madrid, Spain

\section{A R T I C L E I N F O}

Article history:

Available online 21 January 2015

\section{Keywords:}

Untranslated regions

Translation control

IRES elements

RNA structure

RNA-protein interactions

Host factors

\begin{abstract}
A B S T R A C T
Internal ribosome entry site (IRES) elements were discovered in picornaviruses. These elements are cis-acting RNA sequences that adopt diverse three-dimensional structures and recruit the translation machinery using a $5^{\prime}$ end-independent mechanism assisted by a subset of translation initiation factors and various RNA binding proteins termed IRES transacting factors (ITAFs). Many of these factors suffer important modifications during infection including cleavage by picornavirus proteases, changes in the phosphorylation level and/or redistribution of the protein from the nuclear to the cytoplasm compartment. Picornavirus IRES are amongst the most potent elements described so far. However, given their large diversity and complexity, the mechanistic basis of its mode of action is not yet fully understood. This review is focused to describe recent advances on the studies of RNA structure and RNA-protein interactions modulating picornavirus IRES activity.
\end{abstract}

(C) 2015 Elsevier B.V. All rights reserved.

\section{Picornavirus genome organization}

Picornaviruses are non-enveloped positive strand RNA viruses with an icosahedral capsid, which cause important diseases in humans and animals, such as common-cold illnesses, polio, or chronic livestock infections. Picornaviruses are currently classified into 26 genera (Table 1), and unassigned species continue to be described (http://www.picornaviridae.com/). It is widely accepted that the entire life cycle of all picornaviruses occurs in the cytoplasm of the infected cell. Their genome consists of a singlestranded RNA that harbors a single open reading frame (ORF) region flanked by a long 5'UTR and a short poly-(A) tail at the $3^{\prime}$ end. The genome size ranges between about 7100 nts in Tremovirus and 9200 nts in Erbovirus, not taking into consideration the poly(C) tracts (which vary from $50 \mathrm{nts}$ in Cardiovirus to more than $500 \mathrm{nts}$ in some Aphthovirus isolates), and the poly(A) tail (about $50 \mathrm{nts}$ ).

Viral proteins are encoded in a long ORF, translated into a single polyprotein ( $\sim 2300$ amino acids), which is co- and posttranslational processed. Picornavirus polyproteins share a common general organization (Fig. 1). The P1 region comprises the capsid proteins while the $\mathrm{P} 2$ and $\mathrm{P} 3$ regions comprise the replication proteins. In a few cases, the leader (L) protein precedes the P1 region.

\footnotetext{
* Corresponding author. Tel.: +34 911964619; fax: +34 911964420.

E-mail address: emartinez@cbm.csic.es (E. Martínez-Salas).
}

Only in the genome of Dicipivirus (a dicistronic virus isolated from dogs), an intergenic region (IGR) separates two ORFs (Woo et al., 2012).

The polyprotein of all picornaviruses contain embedded proteinases that catalyze cleavages in cis and in trans in a processing cascade (Hanecak et al., 1982; Parks et al., 1989; Skern et al., 1991; Toyoda et al., 1986). Primary cleavages of the polyprotein are mediated by the $3 \mathrm{C}$ proteinase $\left(3 \mathrm{C}^{\mathrm{pro}}\right)$, a serine-proteinase with a cysteine active site (Seipelt et al., 1999). Enterovirus 3C ${ }^{\text {pro }}$ cleaves between $\mathrm{Q}$ and $\mathrm{G}$ pairs while aphthovirus $3 \mathrm{C}^{\text {pro }}$ accepts $\mathrm{E}$ or $\mathrm{Q}$ at the first position (Sweeney et al., 2007). In all picornaviruses, 3Cpro is responsible for specific secondary cleavages of the capsid and replication protein precursors.

The $2 \mathrm{~A}$ protein, located at the junction between the capsid and replication proteins, differs among picornaviruses. In the case of the entero- and sapeloviruses, $2 \mathrm{~A}$ is a serine proteinase with a HDC catalytic triad (Baxter et al., 2006) that mediates a primary cleavage at the junction of the capsid protein precursor and the replicative domains of the polyprotein. In other genera, $2 \mathrm{~A}$ is either an oligopeptide sequence mediating a translational recoding event (Table 1, aphtho-, erbo-, tescho-, cosa-, and senecaviruses) or a longer protein in which this activity resides in their C-terminal region (cardio-, parecho- and avihepatovirus). Insertion of the aphthovirus $2 \mathrm{~A}$ oligopeptide into a polyprotein was sufficient to detect the individual polypeptides, although the upstream $2 \mathrm{~A}$ product was in molar excess relative to the downstream product 
Table 1

Picornavirus genus, proteases encoded and type of IRES.

\begin{tabular}{|c|c|c|c|}
\hline Genus & Species & Proteases & IRES type \\
\hline \multirow[t]{5}{*}{ Enterovirus } & Human enterovirus A (HEV), enterovirus 71 (EV71) & $2 \mathrm{~A}, 3 \mathrm{C}$ & I \\
\hline & Coxsackievirus B (CVB) (human enterovirus B) & $2 \mathrm{~A}, 3 \mathrm{C}$ & I \\
\hline & Poliovirus (PV) (human enterovirus C) & $2 \mathrm{~A}, 3 \mathrm{C}, 3 \mathrm{CD}$ & I \\
\hline & Bovine enterovirus (BEV) & $2 \mathrm{~A}, 3 \mathrm{C}$ & I \\
\hline & Human rhinovirus (HRV) & $2 \mathrm{~A}, 3 \mathrm{C}, 3 \mathrm{CD}$ & I \\
\hline \multirow[t]{2}{*}{ Cardiovirus } & Encephalomyocarditis virus (EMCV) & 3C, (2A CHISEL) & II \\
\hline & Theilovirus (TMEV) & 3C, (2A CHISEL) & II \\
\hline \multirow{3}{*}{ Aphthovirus } & Foot-and-mouth disease virus (FMDV) & L, 3C, (2A CHISEL) & II \\
\hline & Equine rhinitis A virus (ERAV) & L, 3C, (2A CHISEL) & II \\
\hline & Bovine rhinitis B virus (BRBV) & L, 3C, (2A CHISEL) & II \\
\hline Erbovirus & Equine rhinitis B virus (ERBV) & L, 3C, (2A CHISEL) & II \\
\hline Hepatovirus & Hepatitis A virus (HAV) & $3 C$ & III \\
\hline Parechovirus & Human parechovirus (HPeV) & 3C, (2A CHISEL) & II \\
\hline Kobuvirus & Aichi virus (AiV) & $3 \mathrm{C}$ & II \\
\hline Teschovirus & Porcine teschovirus (PTV-1) & 3C, (2A CHISEL) & HCV-like B \\
\hline Sapelovirus & Porcine sapelovirus (PSV, PEV-8), simian sapelovirus (SPV9), simian virus (SV2) & $2 \mathrm{~A}, 3 \mathrm{C}$ & HCV-like B \\
\hline Senecavirus & Seneca Valley virus (SVV) & 3C, (2A CHISEL) & HCV-like A \\
\hline Tremovirus & Avian encephalomyelitis virus (AEV) & $3 C$ & HCV-like A \\
\hline Avihepatovirus & Duck hepatitis A virus (DHAV) & 3C, (2A CHISEL) & HCV-like \\
\hline Megrivirus & Duck megrivirus & $2 \mathrm{~A} 1-2 \mathrm{~A} 2-2 \mathrm{~A} 3,3 \mathrm{C}$ & HCV-like B \\
\hline Dicipivirus & Cadicivirus A & $3 \mathrm{C}, 2 \mathrm{~A}$ & IRES, IGR \\
\hline Aquamavirus & Aquamavirus A & $3 C$ & $?$ \\
\hline Avisivirus & Avisivirus A & $3 C$ & II \\
\hline Cosavirus & Cosavirus A & 3C, (2A CHISEL) & II \\
\hline Gallivirus & Gallivirus A & $3 C$ & II? \\
\hline Hunnivirus & Hunnivirus A & $3 C$ & II \\
\hline Mischivirus & Mischivirus A & $3 C$ & $?$ \\
\hline Mosavirus & Mosavirus A & $3 C$ & $?$ \\
\hline Oscivirus & Oscivirus A & $2 \mathrm{~A}, 3 \mathrm{C}$ & HCV-like B \\
\hline Pasivirus & Pasivirus A & $3 C$ & $?$ \\
\hline Passerivirus & Passerivirus A & $3 C$ & $?$ \\
\hline Rosavirus & Rosavirus A & $3 C$ & $?$ \\
\hline Salivirus & Salivivirus A & $2 A ?, 3 C$ & HCV-like B \\
\hline
\end{tabular}

? represents unknown.

(Donnelly et al., 2001). These results lead to the proposal that 2A was a translational recoding element (CHYSEL for cis-acting hydrolytic element, also referred to as stop/go translation).

Aphtho- and erbovirus polyproteins undergo an additional processing in which the leader protein $\left(\mathrm{L}^{\text {pro }}\right)$ self-cleaves from the polyprotein (Fig. 1). The aphthovirus proteinase exists in two forms (designated Lab and $\mathrm{Lb}$ ) derived from initiation of translation at either of two in-frame AUG codons (Cao et al., 1995). $\mathrm{L}^{\text {pro }}$ is a papain-like protease (Guarne et al., 1998) that recognizes substrates rich in basic residues (Pineiro et al., 2012; Steinberger et al., 2014).

\section{Features of the picornavirus untranslated region}

The genomic RNA of picornaviruses differs from the cellular RNAs in two critical features. First, they do not contain a cap structure at the $5^{\prime}$ end. Instead, a viral protein (VPg) is covalently linked to the $5^{\prime}$ UTR. Second, an internal cis-acting region within the $5^{\prime}$ UTR,

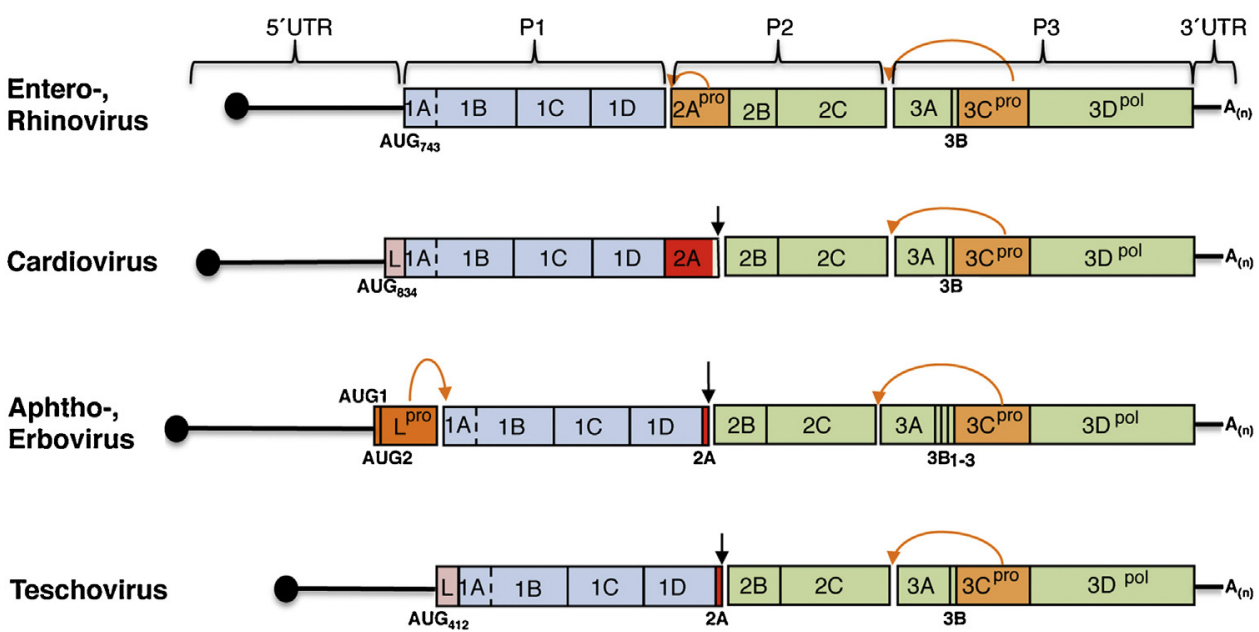

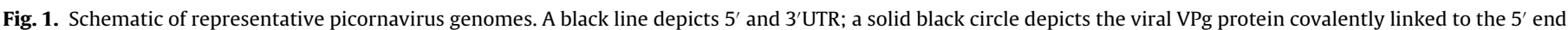

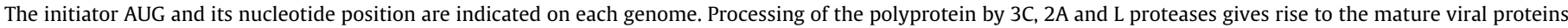

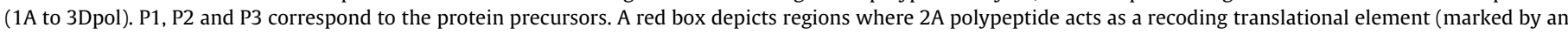
arrow), while pink box depicts cases where the L protein lacks protease activity. 
designated internal ribosome entry site (IRES) element, governs the recruitment of the ribosomal subunits using a process independent of the cap-binding protein eIF4E.

IRES elements were initially reported in poliovirus (PV) and encephalomyocarditis virus (EMCV) RNAs (Jang et al., 1988; Pelletier and Sonenberg, 1988; Trono et al., 1988). These elements are cis-acting RNA regulatory sequences endowed with the capacity to govern cap-independent translation initiation in mRNAs that are translated when cap-dependent translation is compromised. Subsequent studies demonstrated that IRES elements drive internal initiation of translation in the RNA of all members of the Picornaviridae family (Bakhshesh et al., 2008; Borman and Jackson, 1992; Brown et al., 1991; Hinton and Crabb, 2001; Hinton et al., 2000; Kaku et al., 2002; Kuhn et al., 1990; Nateri et al., 2000; Sweeney et al., 2012; Willcocks et al., 2011; Yu et al., 2011b). The genome of other RNA viruses also contains IRES elements, as illustrated by hepacivirus, pestivirus, dicistrovirus, retrovirus (Honda et al., 1996; Tsukiyama-Kohara et al., 1992; Vallejos et al., 2010; Wilson et al., 2000), as well as some RNA viruses infecting plants and protozoa (reviewed in Martinez-Salas et al., 2012). Although the presence of an IRES element is a common feature of all picornavirus RNAs, some differences affecting the organization of the $5^{\prime} \mathrm{UTR}$, described below, are specific of each genus.

The first $84-86$ nts of the $5^{\prime}$ UTR within the genome of enteroviruses adopt a cloverleaf structure (Fig. 2A). In the genome of $\mathrm{PV}$, the prototype member of enterovirus, this RNA structure provides the binding site for the host cellular protein poly(rC)-binding protein 2 (PCBP2) and the viral protein 3CD (Gamarnik and Andino, 1998) leading to the generation of a functional bridge between the $5^{\prime}$ and $3^{\prime}$ ends that facilitates viral replication. Toward the $3^{\prime}$ of the $5^{\prime}$ UTR, two C-rich motifs within the spacer region between the cloverleaf and the IRES element, conserved among entero- and rhinoviruses, are involved in viral RNA replication (Toyoda et al., 2007).

The 5'UTR of cardio- and aphthovirus genomes are significantly longer than the enterovirus counterparts (Fig. 2B). Briefly, from $5^{\prime}$ to $3^{\prime}$ direction the $5^{\prime}$ UTR comprises a long hairpin (termed S, ranging from 40 nts in kobuvirus, 86 nts in cardiovirus, to $367 \mathrm{nts}$ in aphthovirus). This is followed by a polyC-tract (varying from 50 Cs in cardiovirus to $100-500$ in aphthovirus isolates), two to five pseudoknots (Pk) in cardio-, aphtho-, kobu-, parecho-, and hepatovirus, the cis-acting replication element (cre) only in aphthovirus, and finally, the IRES element (see Martinez-Salas et al., 2008 for a review).

\subsection{Protein synthesis initiation site}

Despite the presence of many upstream AUG triplets, initiation of translation in PV RNA occurs at AUG $_{743}$ (Pelletier et al., 1988; Pilipenko et al., 1994). However, a silent $\mathrm{AUG}_{586}$ near a polypyrimidine tract located at a precise distance from the initiator codon is critical for enterovirus multiplication (Pilipenko et al., 1992). Three AUG triplets (designated AUG10,11, and 12) are located within the translation initiation zone in EMCV genome, the prototype member of cardiovirus. Out of the three AUG triplets, AUG11 located at position 834 is recognized as the initiator codon in the context of the viral RNA (Kaminski et al., 1994).

In contrast to EMCV, initiation of protein synthesis in foot-andmouth disease virus (FMDV), the prototype member of aphthovirus, and bovine rhinovirus 2 (BRV2) can occur at two functional inframe AUGs (Belsham, 1992; Hollister et al., 2008). A peculiarity of aphthovirus RNA is that the second AUG triplet (AUG2) is preferentially used to initiate translation (Cao et al., 1995; Lopez de Quinto and Martinez-Salas, 1999). Further information in favor of AUG2 as the functional initiator codon was derived from interference studies using modified oligonucleotides targeting the initiator codons in RNA-transfected cells (Fajardo et al., 2012). A conserved polypyrimidine tract is located $15-25 \mathrm{nts}$ upstream of AUG1, within a single-stranded region that accumulates mutations in viral RNAs isolated from persistently infected cells (MartinezSalas et al., 1993). The second initiator codon, AUG2, is located downstream of an A-rich sequence within a stem-loop that also contains a conserved pyrimidine tract. Recognition of each functional AUG appears to be an independent event, as indicated by the fact that RNAs bearing a substitution of AUG1 to AUA did not modify the frequency of AUG2 recognition. Conversely, enhancement of the initiation frequency at AUG1 did not interfere with initiation at AUG2 (Lopez de Quinto and Martinez-Salas, 1999). However, mechanistic differences in start codon selection exist, since the translation initiation factor eIF1 stimulates initiation complex assembly at AUG2, while eIF1A stimulates assembly at AUG1 (Andreev et al., 2007).

The 5'UTRs of teschovirus (porcine teschovirus-1, PTV-1), Seneca valley virus (SVV) and avihepatovirus (duck hepatitis A virus, DHAV) differ in length and structural motifs (Kaku et al., 2002; Pan et al., 2012). In contrast to other picornavirus, the genome of PTV-1 contains a shorter 5'UTR (Fig. 2C) with an IRES element lacking polypyrimidine tracts. The initiation codon is located at position 412.

\section{Picornavirus-induced modification of host factors}

Picornavirus infections exert a strong influence on the host gene expression as a result of the proteolysis of specific host factors induced by the $2 \mathrm{~A}, \mathrm{~L}$ and $3 \mathrm{C}$ picornavirus proteases (Table 2 ). Indeed, as a consequence of the cleavage of cellular proteins, several processes critical for cell viability are profoundly altered. This is noticed at the level of transcription, mRNA processing, nucleocytoplasmic transport, translation, or RNA granules composition. Among other proteins, proteolysis affects splicing factors, RNAprocessing proteins, RNA helicases, nuclear pore factors, stress granules assembly factors or antiviral response proteins (Almstead and Sarnow, 2007; Barral et al., 2009; Castello et al., 2009; Chase et al., 2014; Chase and Semler, 2014; Chen et al., 2013; Lawrence et al., 2012; Mukherjee et al., 2011; Park et al., 2010; Pineiro et al., 2012; Rozovics et al., 2012; Shiroki et al., 1999; Watters and Palmenberg, 2011; Weng et al., 2009; White et al., 2007).

Particularly well documented is the modification of the host translation machinery, which is subverted to favor viral RNA translation and replication. The mechanisms by which picornavirus infections achieve inhibition of cellular mRNAs translation reside mainly in the cleavage of host translation initiation factors (eIFs) by proteases L, $2 \mathrm{~A}$ or $3 \mathrm{C}$, as well as in the phosphorylation of eIF2 $\alpha$ and other translation factors (Walsh and Mohr, 2011). Specifically, cleavage of eIF4GI, eIF4GII, eIF4AI, eIF3a, eIF5B, and poly(A) binding protein (PABP) (Belsham et al., 2000; Bonderoff et al., 2008; de Breyne et al., 2008a; Gradi et al., 2004; Lamphear et al., 1993; Li et al., 2001; Rodriguez Pulido et al., 2007) induces the inhibition of host protein synthesis and, in general, a shut-down of cellular gene expression.

\section{Translation initiation in eukaryotic cells}

Most cellular mRNAs initiate translation by a mechanism that depends on the recognition of the $\mathrm{m}^{7} \mathrm{G}\left(5^{\prime}\right) \mathrm{ppp}\left(5^{\prime}\right) \mathrm{N}$ structure (termed cap) located at the $5^{\prime}$ end of mRNAs (Sonenberg and Hinnebusch, 2009). In these RNAs, the $5^{\prime}$ cap structure is recognized by eIF4F, a trimeric factor composed of the cap-binding protein eIF4E, the scaffolding protein eIF4G, and the RNA helicase eIF4A (Fig. 3A). The cap-binding capacity of eIF4E is regulated by phosphorylation levels of eIF4E-binding proteins (eIF4E-BP 1-3), 

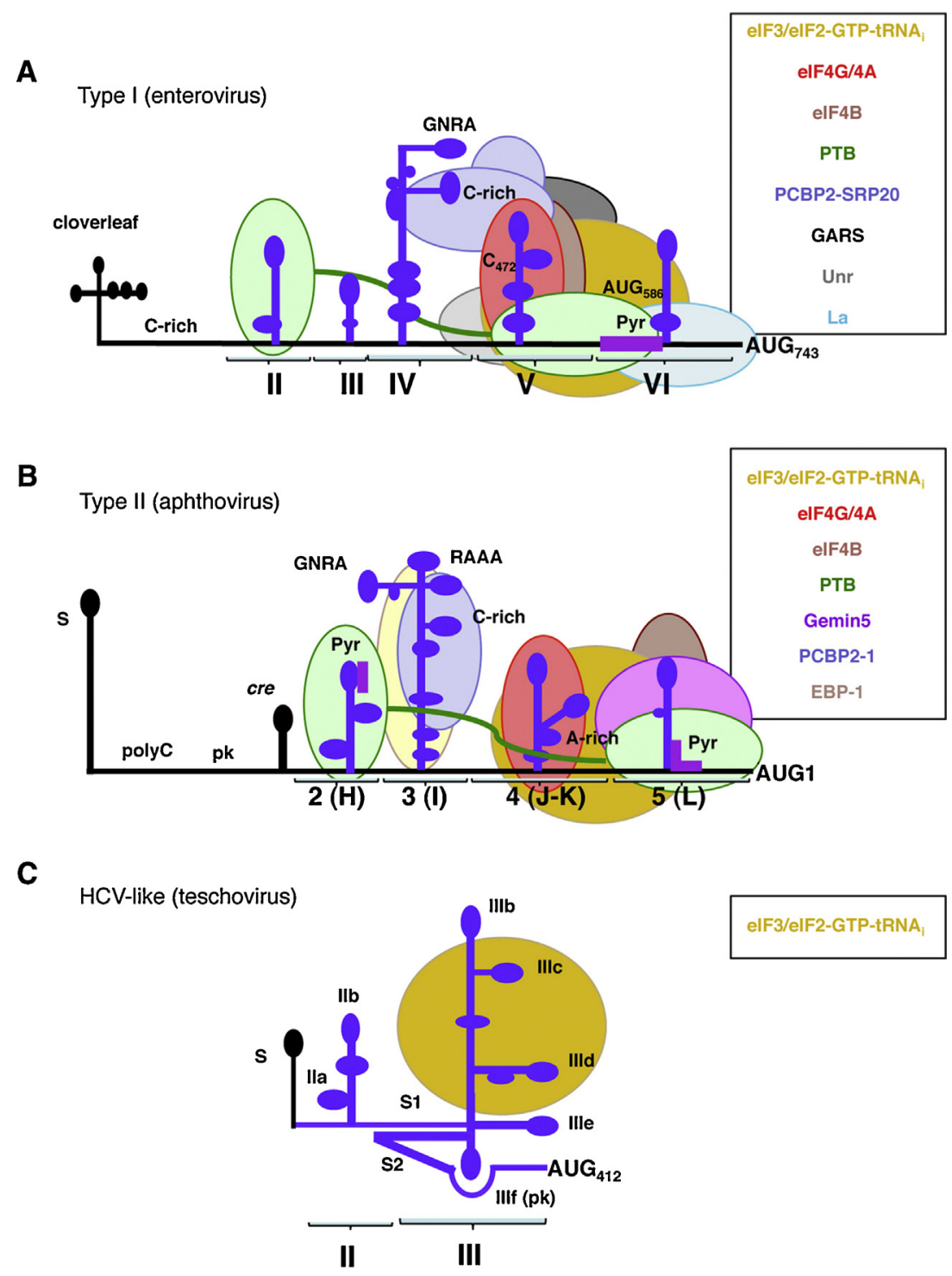

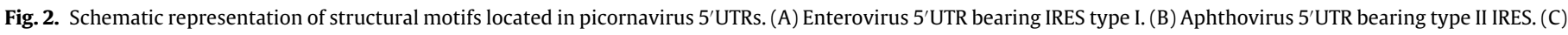

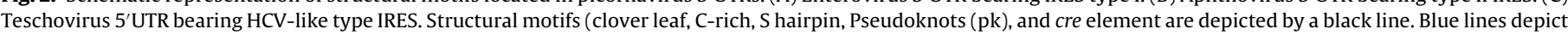

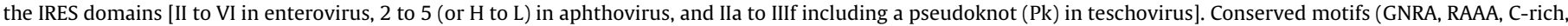

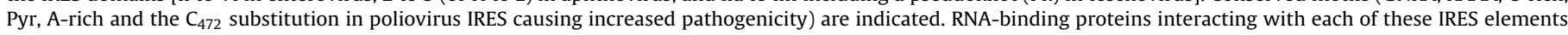
referred to in the text are indicated.

which in turn, depend on the serine/threonine kinase mammalian target of rapamycin (mTOR), resulting in increased levels of protein synthesis due to higher availability of eIF4E. The scaffold protein eIF4G interacts with eIF4A, PABP and the multimeric factor eIF3. In addition, a HEAT motif within the middle region of eIF4G displays RNA binding capacity (Marcotrigiano et al., 2001). eIF3 is a large multisubunit factor that comprises 13 polypeptides in mammalian cells (eIF3a-eIF3m) of which at least eIF3d is involved in direct binding to mRNA, and eIF3a-eIF3c are responsible for RNA interaction with the hepatitis C virus (HCV) IRES (Sun et al., 2013).

Separately, the $43 \mathrm{~S}$ complex that comprises the ternary complex (TC) (consisting of the initiator methionyl-tRNA $A_{i}$ and eIF2-GTP) bound to the $40 \mathrm{~S}$ ribosomal subunit is recruited to the mRNA along with eIF1A, eIF1, eIF3, and eIF5 (Fig. 3A). Assembly of the $43 \mathrm{~S}$ complex into mRNA bound to eIF4F is further stabilized by the interaction of eIF4G with PABP, and of eIF4B with eIF4A and PABP (reviewed in Sonenberg and Hinnebusch, 2009). The 43S complex scans the 5'UTR region of the mRNA until the first initiation codon in the proper context is encountered, leading to the formation of the $48 \mathrm{~S}$ initiation complex. In addition to eIF4A, scanning of highly structured 5'UTRs depends on the RNA helicase DHX29 (Dhote et al., 2012). Other RNA helicases, for instance Ded1, RNA helicase A (RHA), and Dhh1/RCK also play roles in translation initiation, although the molecular mechanisms of their functions remain unclear (see (Parsyan et al., 2011) for a recent review).

Once the $48 \mathrm{~S}$ initiation complex is assembled, eIF1 ensures fidelity of initiation codon selection, discriminating against nonAUG and AUG codons located in poor context. Base pairing between the start codon and the tRNA anticodon triggers a conformational change in the $43 \mathrm{~S}$ complex, leading to $48 \mathrm{~S}$ scanning-incompetent conformation. At this step, eIF5B is required to promote GTP hydrolysis by eIF2 in the $48 \mathrm{~S}$ complex, followed by phosphate release and displacement of eIF1 from its binding site on the 40S subunit. GTP hydrolysis lowers the affinity of eIF2 for the Met-tRNA $A_{i}$, such that eIF2-GDP dissociates and eIF5B replaces it on the Met-tRNA $A_{i}$. Next, eIF5B together with eIF1A promotes the recruitment of the 60S subunit. Finally, ribosomal subunit joining promotes GTP hydrolysis by eIF5B, which dissociates together with eIF1A, leaving a competent 
Table 2

RNA-binding proteins proteolyzed in picornavirus infected cells.

\begin{tabular}{|c|c|c|}
\hline Protein & Role on gene expression & Virus protease (reference) \\
\hline eIF4GI, eIF4GII & Translation initiation & 2A PV, HRV, CBV3, L FMDV (Gradi et al., 2004; Lamphear et al., 1993) \\
\hline eIF4A & Translation initiation & FMDV 3C (Belsham et al., 2000) \\
\hline PABP & Translation initiation & $\begin{array}{l}\text { L FMDV (Rodriguez Pulido et al., 2007), 2A, 3C PV (Bonderoff et al., 2008), 2A } \\
\text { HRV, 2A CVB3 }\end{array}$ \\
\hline eIF3a & Translation initiation & FMDV (Rodriguez Pulido et al., 2007) \\
\hline eIF5B & Translation initiation & PV 3C (de Breyne et al., 2008a) \\
\hline PTB & IRES-dependent translation & $\begin{array}{l}\text { HRV, PV 3CD (Back et al., 2002; Chase et al., 2014), FMDV (Rodriguez Pulido } \\
\text { et al., 2007), HAV 3C (Kanda et al., 2010) }\end{array}$ \\
\hline РСBР2 & Switch from translation to RNA replication & HRV, PV 3CD (Chase et al., 2014; Chase and Semler, 2014) \\
\hline CstF-64 & Cellular polyadenylation & EV71 3C (Weng et al., 2009) \\
\hline FBP2/KSRP & Transcription activation, mRNA decay & EV71 3C (Chen et al., 2013) \\
\hline La & RNA polymerase III transcription & PV 3C (Shiroki et al., 1999) \\
\hline AUF1 & mRNA stability & PV (Rozovics et al., 2012) \\
\hline Gemin3 & RNA helicase, U snRNP assembly & PV 2A (Almstead and Sarnow, 2007) \\
\hline Gemin5 & SMN complex, IRES-dependent repressor & FMDV L (Pineiro et al., 2012) \\
\hline Nup62, Nup98, Nup153 & Nuclear pore & $\begin{array}{l}\text { PV Rhino 2A (Castello et al., 2009; Park et al., 2010; Watters and Palmenberg, } \\
\text { 2011) }\end{array}$ \\
\hline G3BP1-2 & Stress granules assembly & PV 3C (White et al., 2007) \\
\hline Sam68 & Signal transduction and activation of RNA & FMDV 3C (Lawrence et al., 2012) \\
\hline Nup62, Nup98, Nup153 & Nuclear pore & $\begin{array}{l}\text { PV Rhino 2A (Castello et al., 2009; Park et al., 2010; Watters and Palmenberg, } \\
\text { 2011) }\end{array}$ \\
\hline RIG-1 & Antiviral response & Barral et al. (2009) \\
\hline MAVS, TRIF & Antiviral response & CBV3 3C (Mukherjee et al., 2011) \\
\hline IRF7 & Antiviral response & FMDV 3C (Du et al., 2014) \\
\hline
\end{tabular}

$80 \mathrm{~S}$ ribosome with a Met-tRNA $\mathrm{i}_{\mathrm{i}}$ in the P-site ready for translation elongation (reviewed in Parsyan et al., 2011).

\section{IRES-dependent translation initiation in picornavirus RNAs}

As mentioned above, cap-dependent translation initiation is inhibited in picornavirus-infected cells. In addition to eIF4G and PABP proteolysis, eIF4E is targeted in EMCV and PV infected

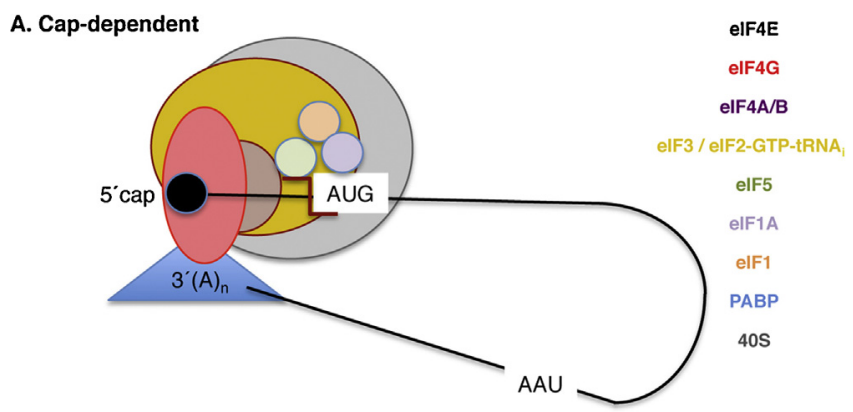

B. IRES-dependent

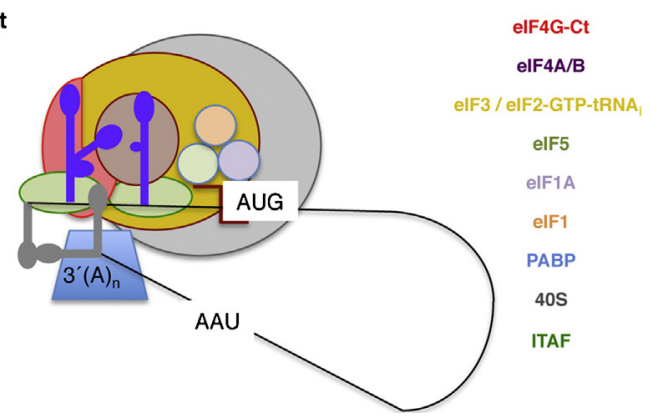

Fig. 3. Cap-dependent (A) and IRES-dependent (B) translation initiation. For simplicity, only main factors referred to in the text have been represented, using the color code used in Fig. 2. The interaction between eIF4G and PABP leads to a functional pseudo-circularization of cellular mRNAs. In the case of the FMDV genome, the $5^{\prime}-3^{\prime}$ long-range interactions between the $3^{\prime} \mathrm{UTR}$ and the S fragment, as well as the 3'UTR-IRES interaction, allows a similar situation presumably stabilized by RNA-binding factors. cells through dephosphorylation of 4E-BPs (Gingras et al., 1996). Hypophosphorylated 4E-BPs bind strongly to eIF4E preventing the binding to eIF4G, and thus, inactivating cap-dependent translation. These adverse situations, however, allow translation of picornavirus RNAs that evade translation shutdown taking advantage of IRES elements. In these RNAs, translation initiation complex is not anchored through the most $5^{\prime}$ end of the RNA. Instead, the $40 \mathrm{~S}$ ribosomal subunit is recruited internally (Fig. 3B), in a process guided jointly by certain RNA structural motifs, a subset of eIFs and a number of RNA-binding proteins (RBPs). Translation of picornaviruses RNA is, therefore, resistant to cap-dependent shutdown.

Viral IRES are characterized by the presence of ignored AUGs upstream of the functional start codon, heavy RNA structure and high GC content (Balvay et al., 2009; Lopez-Lastra et al., 2010; Martinez-Salas, 2008; Plank and Kieft, 2012). Yet, despite performing the same function, IRES elements differ in nucleotide sequence, RNA secondary structure and trans-acting factors requirement. A distinctive feature of picornavirus IRES is their long length, which vary from 280 to 460 nts depending on the genus. According to RNA secondary structure, picornavirus IRES have been classified into different types (designated I, II, III, and HCV-like that, in turn, include subtypes A and B) (Belsham, 2009; Hellen and de Breyne, 2007; Martinez-Salas et al., 2008).

Although some eIFs are modified in picornavirus-infected cells, IRES-dependent translation initiation depends on several eIFs, with the exception of eIF4E. One of these factors is the proteolytic form of the eIF4G factor. Despite being unable to direct cap-dependent translation, the C-terminal fragment of eIF4G is fully efficient in some picornavirus IRES-driven translation. Accordingly, reconstitution assays have shown that assembly of $48 \mathrm{~S}$ initiation complexes into IRES elements belonging to types I and II require the C-terminal end of eIF4G, in addition to eIF4A, and eIF3 (Andreev et al., 2007; de Breyne et al., 2009; Kolupaeva et al., 1998; Ohlmann et al., 1996; Pestova et al., 1996; Sweeney et al., 2014; Yu et al., 2011a). These data, however, have been recently challenged by results obtained in vitro with the EMCV IRES reporting 40S recruitment in the absence of both eIF4G and eIF4A (Chamond et al., 2014). Whether this property applies exclusively to EMCV and/or it occurs only under the conditions used in the in vitro binding assay needs to be elucidated in future studies. 
In contrast to type I and II, type III IRES activity (represented by hepatitis A virus, HAV) depends on intact eIF4G (Ali et al., 2001), and the HCV-like IRES elements do not need eIF4G to assemble 48S complexes in in vitro reconstitution assays (Pisarev et al., 2004).

\subsection{Picornavirus IRES elements diversity}

Picornavirus IRES elements differ strongly in primary sequence and secondary RNA structure. The relationship between RNA structure and biological function of types I and II has been analyzed by mutational analysis and RNA probing (Bailey and Tapprich, 2007; Fernandez et al., 2013; Haller and Semler, 1992; Haller et al., 1996; Malnou et al., 2002; Serrano et al., 2009). Additionally, RNA modeling agrees with the experimental observation that mutations disrupting certain stems impaired IRES activity, and conversely, compensatory mutations restored IRES function (Hoffman and Palmenberg, 1996; Martinez-Salas et al., 1996).

Type I IRES elements, typically present in enteroviruses and rhinovirus RNAs, span about 450 nts organized in five domains that correspond to stem-loops II-VI. Along these stem-loops, conserved nts occur at the base of domain II, in domain IV and in the central and basal half of domain V (Fig. 2A). Noteworthy, domain IV harbors a GNRA motif (N stands for any nucleotide, and R, purine) (Bailey and Tapprich, 2007; Du et al., 2004) and the C-rich loop, also conserved in type II IRES elements. Domain V plays a critical role in PV life cycle (Guest et al., 2004). This stem-loop harbors a major determinant of PV neurovirulence, as indicated by the mutation at position 472 found in Sabin 3 strains recovered from vaccinated patients that developed poliomyelitis (Evans et al., 1985). In support of its relevance for IRES function, domain $\mathrm{V}$ provides the binding site for eIF4G and eIF4A during 48S complex assembly (de Breyne et al., 2009), in addition to several host factors involved in internal initiation.

Cardio- and aphthovirus RNAs harbor type II IRES elements. Although their length is similar to type I, their RNA structure is arranged in modular domains (designated $\mathrm{H}$ to L, or 1 to 5) (Fig. 2B). Uniquely to FMDV RNA, domain 1 partially overlaps with the cre element (Mason et al., 2002). Domain 2 contains a conserved pyrimidine tract that provides a binding site for the polypyrimidine tract binding protein (PTB) (Jang and Wimmer, 1990; Luz and Beck, 1991). Domain 3 is a self-folding cruciform structure that harbors three conserved motifs (GNRA, RAAA, and the C-rich loop) (Fernandez et al., 2011b; Fernandez-Miragall et al., 2009). The data derived from functional analysis were in full agreement with the conservation of structural motifs in highly variable viral genomes, as well as with data from covariation analysis and computational RNA modeling which were used to define stable stems all along the FMDV IRES (Fernandez et al., 2011a; Jung and Schlick, 2013). Interestingly, the GNRA motif and the C-rich loop are conserved in IRES elements classified as type I or II (Fernandez et al., 2011a; Yu et al., 2011b). The GNRA motif, which is essential for IRES activity in both FMDV and EMCV (Lopez de Quinto and Martinez-Salas, 1997; Robertson et al., 1999), adopts a tetraloop conformation (Fernandez-Miragall and Martinez-Salas, 2003; Phelan et al., 2004), and determines long-range interactions (Fernandez-Miragall et al., 2006; Ramos and Martinez-Salas, 1999). Domain 4 consists of a Yshape RNA structure (corresponding to subdomains $\mathrm{J}$ and $\mathrm{K}$ ) and provides the binding-site for eIF4G (Bassili et al., 2004; Kolupaeva et al., 1998; Lopez de Quinto and Martinez-Salas, 2000; Lozano et al., 2014). Finally, domain 5 consists of a short hairpin with a conserved pyrimidine tract on its $3^{\prime}$ end that provides the binding site for eIF4B and PTB (Lopez de Quinto et al., 2001; Meyer et al., 1995), besides other RNA-binding proteins (Pacheco et al., 2008).

The only representative of type III is the HAV IRES, a weak element in comparison to types II and I. However, several mutations that enhance IRES activity in certain cell lines have been reported
(Schultz et al., 1996), which suggest the need for specific factors to stimulate its efficiency.

As refer to by the name, the HCV-like elements resemble the HCV IRES (Belsham, 2009). The HCV IRES element (TsukiyamaKohara et al., 1992), which is located closer to the $5^{\prime}$ end of the viral genome than the picornavirus type II and I described above, is arranged in structural domains II, III and IV with a specific distribution of functions. Whereas domain II accommodates the mRNA in the tRNA-exit site of the ribosome and mediates eIF2 release during $80 \mathrm{~S}$ assembly, domain III participates in the interaction with eIF3 and the $40 \mathrm{~S}$ ribosomal subunit. Additionally, a pseudoknotted structure located upstream of the AUG start codon within domain IV determines translation initiation (reviewed in Fraser and Doudna, 2007).

Concerning the HCV-like picornavirus IRES elements, early studies carried out on the PTV-1 IRES showed that the functional element spans only $280 \mathrm{nts}$ (Chard et al., 2006b). A secondary structure model for the PTV-1 IRES (Chard et al., 2006b) predicted domains II and III, but in contrast to the HCV IRES, domain IV was lacking. In turn, domain III included subdomains IIId and IIIe, and a pseudoknot (Pk) in subdomain IIIf (Fig. 2C). Mutations within the loop of domain IIIe strongly inhibited IRES function. Similarly, disruption of the pseudoknot inhibited IRES activity, and conversely, mutants inserting compensatory mutations in S1 and S2 stems displayed enhanced IRES function (Chard et al., 2006b).

$\mathrm{HCV}$-like IRES elements are also found in the genome of sapelovirus, porcine enterovirus (PEV-8) and simian virus (SV2) (Table 1). Deletion analyses showed that the PEV-8 functional element spans 285 nts, while the SV2 IRES is 440 nts long (Chard et al., 2006a). Domain IIIe and the pseudoknot were conserved in the PEV-8 and SV2 sequences. Sequence comparisons suggested some similarities between the avian encephalomyelitis virus (AEV) and the PTV-1 and SV2 IRES elements. On the basis of sequence conservation among HCV-like IRES it has been predicted that some of these elements may have arose by recombination, and that similar elements may exist in other picornavirus genomes (Hellen and de Breyne, 2007) such as DHAV, SVV, a seal picornavirus, and several picornaviruses isolated from birds (Liao et al., 2014).

The specific requirements for PTV-1 IRES translation initiation were examined using toeprinting analysis. It was found that $48 \mathrm{~S}$ complexes could be formed on the RNA in the presence of $40 \mathrm{~S}$ subunits plus eIF3, eIF2/GTP/met-tRNA (Fig. 2C) (Pisarev et al., 2004). The requirements for $48 \mathrm{~S}$ complex formation on the simian picornavirus SPV9 IRES were similar to those for PTV-1 IRES, but in contrast to HCV IRES, eIF4F and eIF4B stimulated the formation of $48 \mathrm{~S}$ complexes (de Breyne et al., 2008b). It is interesting to note that the AEV IRES, like the SPV9 IRES, showed partial requirement for eIF4F components (Bakhshesh et al., 2008). These results suggest mechanistic differences with the HCV IRES that need to be analyzed in further studies.

\section{RNA-protein interactions involved in picornavirus IRES activity}

In addition to the eIFs described in the above sections, auxiliary factors termed IRES-transacting factors (ITAFs) contribute to modulate (either stimulate or repress) IRES activity. Early studies demonstrated that poliovirus IRES activity in reticulocyte lysates was dependent on the addition of factors present in HeLa cells (Dorner et al., 1984). More recently it has been shown that ITAFs stimulate the assembly of $48 \mathrm{~S}$ complex in vitro on the cardio- and aphthovirus IRES (Andreev et al., 2007; Pilipenko et al., 2000, 2001; Yu et al., 2011a). These data, together with the observation that a truncated IRES sequence having the capacity to interact with eIF4G, eIF3, eIF4B and PTB is not sufficient to promote full IRES 
activity (Fernandez-Miragall et al., 2009), demonstrate that additional factors cooperate in this process.

ITAFs are proteins often identified previously as factors involved in transcription regulation, splicing, RNA transport, RNA stability, or translation control. Multifunctional proteins that function as ITAFs are PTB, PCBP2, the SR splicing factor (SRp20), the far upstream element binding protein 2 (FBP2), the lupus antigen (La), unr (upstream of N-ras), nucleolin, or Gemin5, among others (Bedard et al., 2007; Blyn et al., 1997; Boussadia et al., 2003; Hunt et al., 1999; Jang and Wimmer, 1990; Lin et al., 2009a; Pacheco et al., 2009) (Table 3).

\subsection{ITAFs stimulating IRES activity}

Independent studies carried out by different researchers have identified various members of the heterogeneous nuclear ribonucleoprotein (hnRNP) family associated with picornavirus IRES elements. PTB (also known as hnRNP I) was the first protein reported as an ITAF that stimulated the activity of cardio- and aphthovirus IRES (Fig. 2B) (Jang and Wimmer, 1990; Luz and Beck, 1991). This protein harbors four RNA recognition motifs (RRM) that recognize U/C-rich sequences (Conte et al., 2000). Several picornavirus IRES elements have two polypyrimidine tracts located at each end of the IRES region. In agreement with the functional role of each pyrimidine tract on IRES activity it has been found that PTB constrains the EMCV IRES structure in a unique orientation by binding to the RNA with RRM1-2 contacting the $3^{\prime}$ end, and RRM3 contacting the $5^{\prime}$ end of the IRES (Kafasla et al., 2009).

Other members of the hnRNP family identified associated to picornavirus IRES are hnRNP K, PCBP1 (hnRNP E1) and PCBP2 (hnRNP E2) (Choi et al., 2004; Lin et al., 2008). These proteins recognize poly-r $(\mathrm{C})$ regions and share the KH RNA-binding domain. In particular, PCBP2 stimulates the activity of PV, HRV and CBV3 IRES (Gamarnik et al., 2000; Sean et al., 2009). However, although PCBP2 binds to both EMCV and FMDV IRES, this factor only stimulates the first one (Walter et al., 1999).

Most ITAFs are generally associated in large ribonucleoprotein complexes with various factors. Given the ability of RBPs to recognize multiple targets (reviewed in Lunde et al., 2007), it is not surprising that secondary protein-protein or RNA-protein bridges could facilitate IRES activity. An illustrative example of a functional protein-protein bridge is provided by the splicing factor SRp20 (Fig. 2A) which up-regulates PV IRES-mediated translation via its interaction with PCBP2 (Bedard et al., 2007). Another example of this type of functional bridges is Ebp1 (erbB-3-binding protein 1 , also known as $\mathrm{ITAF}_{45}$ ), which cooperates with PTB to stimulate FMDV IRES activity (Pilipenko et al., 2000). Ebp1 protein, however, does not affect EMCV IRES activity (Monie et al., 2007).

A common feature of many ITAFs is the fact of being predominantly nuclear proteins, which become displaced to the cytoplasm in infected cells. One of the first reported examples was nucleolin (Waggoner and Sarnow, 1998) that interacts with HAV, EMCV and PV IRES (Kim and Jang, 1999). Recent studies have shown the localization in the cytoplasm of infected cells of several ITAFs, as illustrated by far upstream element binding protein 1 (FBPI) (Huang et al., 2011) or hnRNP A (Lin et al., 2009b). Redistribution of SRp20 to the cytoplasm of infected cells (Fitzgerald et al., 2013; Fitzgerald and Semler, 2011) is consistent with their capacity to stimulate enterovirus 71 (EV71) or PV IRES activity (Bedard et al., 2007).

\subsection{ITAFs dowregulating IRES activity}

Although early studies identified ITAFs as proteins stimulating IRES activity, various examples of IRES downregulators have also been found in later studies. For instance, the nuclear protein FBP2 is a KH protein that shuttles to the cytoplasm in infected cells negatively regulating EV71 IRES activity (Lin et al., 2009a). The double stranded RNA-binding protein DRBP76:NF45 is also a nuclear heterodimeric protein that interacts with HRV IRES repressing its activity in neuron-derived cells (Merrill and Gromeier, 2006). Similarly, the cellular mRNA decay protein AU-binding factor (AUF1) behaves as a negative regulator of EV71 and HRV infections (Cathcart et al., 2013). Another example of a repressor ITAF is Gemin5, a cytoplasmic protein that binds directly to the FMDV IRES (Pineiro et al., 2013) (Fig. 2B) down-regulating translation. Earlier studies reported that Gemin 5 was the RNA-binding factor of the survival of motor neurons (SMN) complex, a ribonucleoprotein aggregate that assembles the seven member ( $\mathrm{Sm}$ ) proteins on snRNAs, the components of the splicing machinery (Battle et al., 2006). Using independent approaches it was found that Gemin5 was retained in $\mathrm{m}^{7} \mathrm{GTP}$ resin (Bradrick and Gromeier, 2009), explaining its down-regulatory role of cap-dependent translation (Pacheco et al., 2009). Thus, ITAFs are generally multifunctional proteins, a characteristic explaining their capacity to act at many layers of gene expression control.

\subsection{Modified ITAFs in infected cells and IRES activity}

A characteristic feature of some ITAFs is their recognition by picornavirus-encoded proteases (Table 2). As a consequence of being substrate of these enzymes, the fragments resulting from the proteolytic cleavage have different capacity to modulate translation than the original unfragmented polypeptide. This property has been described for PTB, Gemin5 or FBP2. In the case of PTB, the PV $3 C / 3 C D$ protease recognizes the three isoforms of PTB generating truncated polypeptides that repress IRES activity (Back et al., 2002). Gemin 5 is a substrate of the L protease during the late stages of FMDV infection (Pineiro et al., 2012). Unlike the N-terminal region that harbors $13 \mathrm{WD}$ repeats, the $\mathrm{C}$-terminal region binds to domain 5 of the FMDV IRES. The C-terminal region harbors two noncanonical RNA-binding motifs (designated RBS1 and RBS2). RBS2 displays the translation repressor activity while the polypeptide containing the highest RNA-binding affinity (RBS1) does not interfere IRES-dependent translation (Fernandez-Chamorro et al., 2014). A different example of a repressor ITAF is FBP2, which is proteolyzed in EV71 infected cells. However, in this case the fragment that loses its C-terminal region behaves as an IRES stimulator (Chen et al., 2013).

\subsection{Novel factors enlarging the list of ITAFs}

As a consequence of in depth RNA-protein interaction studies performed with picornavirus IRES, the list of ITAFs is growing incessantly. A new group of ITAFs includes the Glycil tRNA synthetase (GARS), a protein that interacts with stem-loop V of PV IRES (Fig. 2A) stimulating its activity (Andreev et al., 2012). Domain V of the PV IRES uses tRNA(Gly) anticodon stem-loop mimicry to recruit GARS to the apical part of domain $\mathrm{V}$, adjacent to the binding site of eIF4G. The binding of GARS promotes the accommodation of the initiation region of the IRES in the mRNA binding site of the ribosome, enhancing $48 \mathrm{~S}$ initiation complex formation. Whether this data is related to the observation that some specific RNA structural motifs within other picornavirus IRES are substrates of the ribonuclease P (Serrano et al., 2007) (the enzyme responsible for the processing of the tRNA precursor) is still unknown. Nonetheless, it opens the possibility that some parts of the IRES could be remnants of tRNAlike motifs, presumably inherited from ancient RNA motifs adapted to perform new functions. 
Table 3

RNA-binding proteins interacting with picornavirus IRES.

\begin{tabular}{|c|c|c|c|}
\hline Proteins & IRES & Effect & Reference \\
\hline РТВ & FMDV, EMCV, TMEV, PV, HRV, CBV3, HAV & Stimulation & $\begin{array}{l}\text { Gosert et al. (2000), Jang and Wimmer (1990), Kafasla et al. (2009), Luz } \\
\text { and Beck (1991), Verma et al. (2010) }\end{array}$ \\
\hline PCBP1 & PV, HRV & Stimulation & Choi et al. (2004) \\
\hline РCBP2 & PV, HRV, CBV3, EV71, BEV, HAV, EMCV, FMDV\# & Stimulation ${ }^{\#}$ & $\begin{array}{l}\text { Gamarnik et al. (2000), Sean et al. (2009), Walter et al. (1999), Graff } \\
\text { et al. (1998) }\end{array}$ \\
\hline hnRNP A1 & EV71, HRV & Stimulation & Levengood et al. (2013) \\
\hline SRp20 & PV & Stimulation & Bedard et al. (2007) \\
\hline Ebp $1 / \mathrm{ITAF}_{45}$ & FMDV, EMCV\# & Stimulation ${ }^{\#}$ & Monie et al. (2007), Pilipenko et al. (2001) \\
\hline Unr & PV, HRV & Stimulation & Boussadia et al. (2003), Hunt et al. (1999) \\
\hline Nucleolin & PV & & Waggoner and Sarnow (1998) \\
\hline La & PV, CBV3, HRV, EMCV, HAV & Stimulation & Kim and Jang (1999), Ray and Das (2002) \\
\hline FBP1 & EV71 & Stimulation & Huang et al. (2011) \\
\hline AUF1 & EV71 & Repression & Cathcart et al. (2013) \\
\hline FBP2/KSRP & EV71 & Repression & Chen et al. (2013) \\
\hline Gemin5 & FMDV & Downregulation & Pineiro et al. (2013) \\
\hline DRBP76:NF45 & HRV & Repression & Merrill and Gromeier (2006) \\
\hline GARS & PV & Stimulation & Andreev et al. (2012) \\
\hline
\end{tabular}

\# represents no effect.

\section{Implications of long-range $5^{\prime}-3^{\prime}$ viral RNA interactions on IRES activity}

On the opposite end of the picornavirus genome, the $3^{\prime} \mathrm{UTR}$ plays a critical role in virus multiplication (Duque and Palmenberg, 2001; Melchers et al., 1997; Saiz et al., 2001; Todd et al., 1997). This region harbors a heterogeneous sequence, ranging between 42 nts in HRV and $317 \mathrm{nts}$ in DHAV, in addition to a relative short polyA tail. Enterovirus 3'UTR RNA structure models suggest the presence of two stem-loops, with a kissing loop predicted in some instances (Pilipenko et al., 1996; Wang et al., 1999). Various studies support an active role for interactions between the $5^{\prime}$ and $3^{\prime}$ ends of the viral RNA in controlling picornavirus gene expression. For instance, PV IRES activity in neuronal cells was stimulated by the viral 3'UTR (Dobrikova et al., 2003), and the FMDV IRES was stimulated by its own 3'UTR (Garcia-Nunez et al., 2014; Lopez de Quinto et al., 2002), irrespectively of the presence of polyA tail and the coexpression of the L protease.

In addition to RBPs, $5^{\prime}-3^{\prime}$ end bridges involve direct long-distant RNA-RNA contacts (Serrano et al., 2006), likely leading to a pseudocircularization of the viral RNA. It is worth noting that the $3^{\prime}$ end region, which is essential for FMDV infectivity (Saiz et al., 2001), can mediate two different long-range interactions (Serrano et al., 2006), one with the IRES element and another with the $S$ hairpin at the 5 end (Fig. 3B). Long-distant interactions involving the IRES element have also been reported to occur in HCV RNA (Romero-Lopez et al., 2014). These long-range interactions in concerted action with the corresponding protein partners may play a pivotal role in the switch from translation to replication.

Different groups of viral RNAs that have evolved alternative manners to promote cap-independent translation initiation (reviewed in) (Simon and Miller, 2013), trigger translation initiation taking advantage of RNA structures that also generate functional bridges between the $5^{\prime}$ and 3'UTRs of the viral RNA (see (Nicholson and White, 2014) for a comprehensive recent review). Together, these common features provide a mechanistic basis for cap-independent translation stimulation of viral RNAs resembling the synergistic stimulation of the cellular mRNA cap-dependent translation.

\section{Conclusions and perspectives}

The understanding of RNA structure organization and host protein interaction relevant for viral IRES elements function has made considerable progress in recent years (Hashem et al., 2013; Plank and Kieft, 2012). The three-dimensional structure of picornavirus IRES elements is yet unknown despite being the first functional IRES elements ever described, but progress in this direction has being made (Jung and Schlick, 2014; King et al., 2013; Lozano et al., 2014). Noteworthy, understanding the implications of RNA structural elements on the function of these powerful elements will make possible to predict IRES elements in other genomes, either viral or cellular. Attempts to do this using specific RNA structural motifs of type II IRES have been already successful (Dotu et al., 2013). However, given the diversity of primary sequences and secondary RNA structures, there is still much to learn about the interaction of picornavirus IRES elements with host factors and how modification of these factors in infected cells modulates IRES activity. In particular, elucidating the function of IRES-dependent translation demands a deep understanding of the protein partners involved in this process. ITAFs are RBPs that shuttle between the nucleus and the cytoplasm, a situation that is exacerbated in infected cells leading to the reprogramming of gene expression pathways affecting both, the cell and the virus life cycle (Chase and Semler, 2012).

The comparative analysis of the IRES-interacting factors mentioned above and their binding site within the picornavirus IRES reveals critical issues. First, many of these factors are the same or behave in a very similar manner. Second, the binding site of many of these factors tend to accumulate on the $3^{\prime}$ end of the IRES region, specifically within domain $\mathrm{V}$ of IRES belonging to type I and domains 4 and 5 of type II. This is coincident with the fact that these domains anchor eIF4G, an eIF essential for translation initiation driven by these types of picornavirus IRES. Host factors bound to the type III and the HCV-like, different than eIFs, are yet poorly known. Although the composition of the full IRES-assembled complexes needs to be elucidated in more detail, the studies made on types II and I reveal that the proteins identified as ITAFs are not passenger RBPs unspecifically associated to the IRES region. Instead, the non-hazardous binding of ITAFs to the different IRES domains suggests a specific role of these factors during internal initiation of translation. Whether ITAFs help to remodel the RNA structure in a way that enhances its affinity for components of the translation machinery, or if they substitute canonical factors providing functional bridges between the mRNA and the ribosomal subunits needs to be experimentally confirmed in future years. The fast development of powerful methodologies that allow the functional and structural analysis of large ribonucleoprotein complexes will make possible this endeavor. 


\section{Acknowledgements}

This work was supported by grants BFU2011-25437 and CSD2009-00080 from MINECO, and by an Institutional grant from Fundación Ramón Areces.

\section{References}

Ali, I.K., McKendrick, L., Morley, S.J., Jackson, R.J., 2001. Activity of the hepatitis A virus IRES requires association between the cap-binding translation initiation factor (eIF4E) and eIF4G. J. Virol. 75, 7854-7863.

Almstead, L.L., Sarnow, P., 2007. Inhibition of U snRNP assembly by a virus-encoded proteinase. Genes Dev. 21, 1086-1097.

Andreev, D.E., Fernandez-Miragall, O., Ramajo, J., Dmitriev, S.E., Terenin, I.M., Martinez-Salas, E., Shatsky, I.N., 2007. Differential factor requirement to assemble translation initiation complexes at the alternative start codons of foot-and-mouth disease virus RNA. RNA 13, 1366-1374.

Andreev, D.E., Hirnet, J., Terenin, I.M., Dmitriev, S.E., Niepmann, M., Shatsky, I.N., 2012. Glycyl-tRNA synthetase specifically binds to the poliovirus IRES to activate translation initiation. Nucleic Acids Res. 40, 5602-5614.

Back, S.H., Kim, Y.K., Kim, W.J., Cho, S., Oh, H.R., Kim, J.E., Jang, S.K., 2002. Translation of polioviral mRNA is inhibited by cleavage of polypyrimidine tract-binding proteins executed by polioviral 3C(pro). J. Virol. 76, 2529-2542.

Bailey, J.M., Tapprich, W.E., 2007. Structure of the $5^{\prime}$ nontranslated region of the coxsackievirus b3 genome: chemical modification and comparative sequence analysis. J. Virol. 81, 650-668.

Bakhshesh, M., Groppelli, E., Willcocks, M.M., Royall, E., Belsham, G.J., Roberts, L.O., 2008. The picornavirus avian encephalomyelitis virus possesses a hepatitis $C$ virus-like internal ribosome entry site element. J. Virol. 82, 1993-2003.

Balvay, L., Soto Rifo, R., Ricci, E.P., Decimo, D., Ohlmann, T., 2009. Structural and functional diversity of viral IRESes. Biochim. Biophys. Acta 1789, 542-557.

Barral, P.M., Sarkar, D., Fisher, P.B., Racaniello, V.R., 2009. RIG-I is cleaved during picornavirus infection. Virology 391, 171-176.

Bassili, G., Tzima, E., Song, Y., Saleh, L., Ochs, K., Niepmann, M., 2004. Sequence and secondary structure requirements in a highly conserved element for foot-andmouth disease virus internal ribosome entry site activity and eIF4G binding. J. Gen. Virol. 85, 2555-2565.

Battle, D.J., Lau, C.K., Wan, L., Deng, H., Lotti, F., Dreyfuss, G., 2006. The Gemin5 protein of the SMN complex identifies snRNAs. Mol. Cell 23, 273-279.

Baxter, N.J., Roetzer, A., Liebig, H.D., Sedelnikova, S.E., Hounslow, A.M., Skern, T., Waltho, J.P., 2006. Structure and dynamics of coxsackievirus B4 2A proteinase, an enyzme involved in the etiology of heart disease. J. Virol. 80, 1451-1462.

Bedard, K.M., Daijogo, S., Semler, B.L., 2007. A nucleo-cytoplasmic SR protein functions in viral IRES-mediated translation initiation. EMBO J. 26, 459-467.

Belsham, G.J., 1992. Dual initiation sites of protein synthesis on foot-and-mouth disease virus RNA are selected following internal entry and scanning of ribosomes in vivo. EMBO J. 11, 1105-1110.

Belsham, G.J., 2009. Divergent picornavirus IRES elements. Virus Res. 139, 183-192.

Belsham, G.J., McInerney, G.M., Ross-Smith, N., 2000. Foot-and-mouth disease virus $3 \mathrm{C}$ protease induces cleavage of translation initiation factors eIF4A and eIF4G within infected cells. J. Virol. 74, 272-280.

Blyn, L.B., Towner, J.S., Semler, B.L., Ehrenfeld, E., 1997. Requirement of poly(rC) binding protein 2 for translation of poliovirus RNA. J. Virol. 71, 6243-6246.

Bonderoff, J.M., Larey, J.L., Lloyd, R.E., 2008. Cleavage of poly(A)-binding protein by poliovirus $3 \mathrm{C}$ proteinase inhibits viral internal ribosome entry site-mediated translation. J. Virol. 82, 9389-9399.

Borman, A., Jackson, R.J., 1992. Initiation of translation of human rhinovirus RNA: mapping the internal ribosome entry site. Virology 188, 685-696.

Boussadia, O., Niepmann, M., Creancier, L., Prats, A.C., Dautry, F., Jacquemin-Sablon, $\mathrm{H}$, 2003. Unr is required in vivo for efficient initiation of translation from the internal ribosome entry sites of both rhinovirus and poliovirus. J. Virol. 77, 3353-3359

Bradrick, S.S., Gromeier, M., 2009. Identification of gemin5 as a novel 7methylguanosine cap-binding protein. PLoS ONE 4, e7030.

Brown, E.A., Day, S.P., Jansen, R.W., Lemon, S.M., 1991. The 5' nontranslated region of hepatitis A virus RNA: secondary structure and elements required for translation in vitro. J. Virol. 65, 5828-5838.

Cao, X., Bergmann, I.E., Fullkrug, R., Beck, E., 1995. Functional analysis of the two alternative translation initiation sites of foot-and-mouth disease virus. J. Virol. $69,560-563$

Castello, A., Izquierdo, J.M., Welnowska, E., Carrasco, L., 2009. RNA nuclear export is blocked by poliovirus $2 \mathrm{~A}$ protease and is concomitant with nucleoporin cleavage. J. Cell Sci. 122, 3799-3809.

Cathcart, A.L., Rozovics, J.M., Semler, B.L., 2013. Cellular mRNA decay protein AUF1 negatively regulates enterovirus and human rhinovirus infections. J. Virol. 87, 10423-10434.

Chamond, N., Deforges, J., Ulryck, N., Sargueil, B., 2014. 40S recruitment in the absence of eIF4G/4A by EMCV IRES refines the model for translation initiation on the archetype of Type II IRESs. Nucleic Acids Res. 42, 10373-10384.

Chard, L.S., Bordeleau, M.E., Pelletier, J., Tanaka, J., Belsham, G.J., 2006a. Hepatitis C virus-related internal ribosome entry sites are found in multiple genera of the family Picornaviridae. J. Gen. Virol. 87, 927-936.

Chard, L.S., Kaku, Y., Jones, B., Nayak, A., Belsham, G.J., 2006b. Functional analyses of RNA structures shared between the internal ribosome entry sites of hepatitis C virus and the picornavirus porcine teschovirus 1 Talfan. J. Virol. 80 1271-1279.

Chase, A.J., Daijogo, S., Semler, B.L., 2014. Inhibition of poliovirus-induced cleavage of cellular protein PCBP2 reduces the levels of viral RNA replication. J. Virol. 88, 3192-3201

Chase, A.J., Semler, B.L., 2012. Viral subversion of host functions for picornavirus translation and RNA replication. Future Virol. 7, 179-191.

Chase, A.J., Semler, B.L., 2014. Differential cleavage of IRES trans-acting factors (ITAFs) in cells infected by human rhinovirus. Virology 449, 35-44.

Chen, L.L., Kung, Y.A., Weng, K.F., Lin, J.Y., Horng, J.T., Shih, S.R., 2013. Enterovirus 71 infection cleaves a negative regulator for viral internal ribosomal entry sitedriven translation. J. Virol. 87, 3828-3838.

Choi, K., Kim, J.H., Li, X., Paek, K.Y., Ha, S.H., Ryu, S.H., Wimmer, E., Jang, S.K., 2004 Identification of cellular proteins enhancing activities of internal ribosomal entry sites by competition with oligodeoxynucleotides. Nucleic Acids Res. 32, 1308-1317.

Conte, M.R., Grune, T., Ghuman, J., Kelly, G., Ladas, A., Matthews, S., Curry, S., 2000 Structure of tandem RNA recognition motifs from polypyrimidine tract binding protein reveals novel features of the RRM fold. EMBO J. 19, 3132-3141.

de Breyne, S., Bonderoff, J.M., Chumakov, K.M., Lloyd, R.E., Hellen, C.U., 2008a. Cleavage of eukaryotic initiation factor eIF5B by enterovirus 3 C proteases. Virology $378,118-122$.

de Breyne, S., Yu, Y., Pestova, T.V., Hellen, C.U., 2008b. Factor requirements for translation initiation on the Simian picornavirus internal ribosomal entry site. RNA 14, 367-380.

de Breyne, S., Yu, Y., Unbehaun, A., Pestova, T.V., Hellen, C.U., 2009. Direct functional interaction of initiation factor eIF4G with type 1 internal ribosomal entry sites. Proc. Natl. Acad. Sci. U. S. A. 106, 9197-9202.

Dhote, V., Sweeney, T.R., Kim, N., Hellen, C.U., Pestova, T.V., 2012. Roles of individua domains in the function of DHX29, an essential factor required for translation of structured mammalian mRNAs. Proc. Natl. Acad. Sci. U. S. A. 109, E3150-E3159.

Dobrikova, E., Florez, P., Bradrick, S., Gromeier, M., 2003. Activity of a type 1 picornavirus internal ribosomal entry site is determined by sequences within the 3 nontranslated region. Proc. Natl. Acad. Sci. U. S. A. 100, 15125-15130.

Donnelly, M.L., Luke, G., Mehrotra, A., Li, X., Hughes, L.E., Gani, D., Ryan, M.D., 2001 Analysis of the aphthovirus 2A/2B polyprotein 'cleavage' mechanism indicates not a proteolytic reaction, but a novel translational effect: a putative ribosomal ‘skip'. J. Gen. Virol. 82, 1013-1025.

Dorner, A.J., Semler, B.L., Jackson, R.J., Hanecak, R., Duprey, E., Wimmer, E., 1984 In vitro translation of poliovirus RNA: utilization of internal initiation sites in reticulocyte lysate. J. Virol. 50, 507-514.

Dotu, I., Lozano, G., Clote, P., Martinez-Salas, E., 2013. Using RNA inverse folding to identify IRES-like structural subdomains. RNA Biol. 10, 1842-1852.

Du, Y., Bi, J., Liu, J., Liu, X., Wu, X., Jiang, P., Yoo, D., Zhang, Y., Wu, J., Wan, R. Zhao, X., Guo, L., Sun, W., Cong, X., Chen, L., Wang, J., 2014. 3Cpro of foot-andmouth disease virus antagonizes the interferon signaling pathway by blocking STAT1/STAT2 nuclear translocation. J. Virol. 88, 4908-4920.

Du, Z., Ulyanov, N.B., Yu, J., Andino, R., James, T.L., 2004. NMR structures of loop B RNAs from the stem-loop IV domain of the enterovirus internal ribosome entry site: a single $C$ to $U$ substitution drastically changes the shape and flexibility of RNA. Biochemistry 43, 5757-5771.

Duque, H., Palmenberg, A.C., 2001. Phenotypic characterization of three phylogenetically conserved stem-loop motifs in the mengovirus 3' untranslated region. J. Virol. 75, 3111-3120.

Evans, D.M., Dunn, G., Minor, P.D., Schild, G.C., Cann, A.J., Stanway, G., Almond, J.W., Currey, K., Maizel Jr., J.V., 1985. Increased neurovirulence associated with a single nucleotide change in a noncoding region of the Sabin type 3 poliovaccine genome. Nature 314, 548-550.

Fajardo Jr., T., Rosas, M.F., Sobrino, F., Martinez-Salas, E., 2012. Exploring IRES region accessibility by interference of foot-and-mouth disease virus infectivity. PLOS ONE 7, e41382.

Fernandez, N., Buddrus, L., Pineiro, D., Martinez-Salas, E., 2013. Evolutionary conserved motifs constrain the RNA structure organization of picornavirus IRES FEBS Lett. 587, 1353-1358.

Fernandez, N., Fernandez-Miragall, O., Ramajo, J., Garcia-Sacristan, A., Bellora, N., Eyras, E., Briones, C., Martinez-Salas, E., 2011a. Structural basis for the biological relevance of the invariant apical stem in IRES-mediated translation. Nucleic Acids Res. 39, 8572-8585.

Fernandez, N., Garcia-Sacristan, A., Ramajo, J., Briones, C., Martinez-Salas, E., 2011b. Structural analysis provides insights into the modular organization of picornavirus IRES. Virology 409, 251-261.

Fernandez-Chamorro, J., Pineiro, D., Gordon, J.M., Ramajo, J., Francisco-Velilla, R., Macias, M.J., Martinez-Salas, E., 2014. Identification of novel non-canonical RNAbinding sites in Gemin5 involved in internal initiation of translation. Nucleic Acids Res. 42, 5742-5754

Fernandez-Miragall, O., Lopez de Quinto, S., Martinez-Salas, E., 2009. Relevance of RNA structure for the activity of picornavirus IRES elements. Virus Res. 139, $172-182$.

Fernandez-Miragall, O., Martinez-Salas, E., 2003. Structural organization of a viral IRES depends on the integrity of the GNRA motif. RNA 9, 1333-1344

Fernandez-Miragall, O., Ramos, R., Ramajo, J., Martinez-Salas, E., 2006. Evidence of reciprocal tertiary interactions between conserved motifs involved in organizing RNA structure essential for internal initiation of translation. RNA 12, 223-234.

Fitzgerald, K.D., Chase, A.J., Cathcart, A.L., Tran, G.P., Semler, B.L., 2013. Vira proteinase requirements for the nucleocytoplasmic relocalization of cellular splicing factor SRp20 during picornavirus infections. J. Virol. 87, 2390-2400. 
Fitzgerald, K.D., Semler, B.L., 2011. Re-localization of cellular protein SRp20 during poliovirus infection: bridging a viral IRES to the host cell translation apparatus. PLoS Pathog. 7, e1002127.

Fraser, C.S., Doudna, J.A., 2007. Structural and mechanistic insights into hepatitis C viral translation initiation. Nat. Rev. Microbiol. 5, 29-38.

Gamarnik, A.V., Andino, R., 1998. Switch from translation to RNA replication in a positive-stranded RNA virus. Genes Dev. 12, 2293-2304

Gamarnik, A.V., Boddeker, N., Andino, R., 2000. Translation and replication of human rhinovirus type 14 and mengovirus in Xenopus oocytes. J. Virol. 74, 11983-11987.

Garcia-Nunez, S., Gismondi, M.I., Konig, G., Berinstein, A., Taboga, O., Rieder, E., Martinez-Salas, E., Carrillo, E., 2014. Enhanced IRES activity by the 3'UTR element determines the virulence of FMDV isolates. Virology 448, 303-313.

Gingras, A.C., Svitkin, Y., Belsham, G.J., Pause, A., Sonenberg, N., 1996. Activation of the translational suppressor 4E-BP1 following infection with encephalomyocarditis virus and poliovirus. Proc. Natl. Acad. Sci. U. S. A. 93, 5578-5583.

Gosert, R., Chang, K.H., Rijnbrand, R., Yi, M., Sangar, D.V., Lemon, S.M., 2000. Transient expression of cellular polypyrimidine-tract binding protein stimulates cap-independent translation directed by both picornaviral and flaviviral internal ribosome entry sites in vivo. Mol. Cell. Biol. 20, 1583-1595.

Gradi, A., Foeger, N., Strong, R., Svitkin, Y.V., Sonenberg, N., Skern, T., Belsham, G.J., 2004. Cleavage of eukaryotic translation initiation factor 4GII within foot-andmouth disease virus-infected cells: identification of the L-protease cleavage site in vitro. J. Virol. 78, 3271-3278.

Graff, J., Cha, J., Blyn, L.B., Ehrenfeld, E., 1998. Interaction of poly(rC) binding protein 2 with the $5^{\prime}$ noncoding region of hepatitis A virus RNA and its effects on translation. J. Virol. 72, 9668-9675

Guarne, A., Tormo, J., Kirchweger, R., Pfistermueller, D., Fita, I., Skern, T., 1998. Structure of the foot-and-mouth disease virus leader protease: a papain-like fold adapted for self-processing and eIF4G recognition. EMBO J. 17, 7469-7479.

Guest, S., Pilipenko, E., Sharma, K., Chumakov, K., Roos, R.P., 2004. Molecular mechanisms of attenuation of the Sabin strain of poliovirus type 3. J. Virol. 78, 11097-11107.

Haller, A.A., Semler, B.L., 1992. Linker scanning mutagenesis of the internal ribosome entry site of poliovirus RNA. J. Virol. 66, 5075-5086.

Haller, A.A., Stewart, S.R., Semler, B.L., 1996. Attenuation stem-loop lesions in the 5 noncoding region of poliovirus RNA: neuronal cell-specific translation defects. J. Virol. 70, 1467-1474

Hanecak, R., Semler, B.L., Anderson, C.W., Wimmer, E., 1982. Proteolytic processing of poliovirus polypeptides: antibodies to polypeptide P3-7c inhibit cleavage at glutamine-glycine pairs. Proc. Natl. Acad. Sci. U. S. A. 79, 3973-3977

Hashem, Y., des Georges, A., Dhote, V., Langlois, R., Liao, H.Y., Grassucci, R.A., Pestova, T.V., Hellen, C.U., Frank, J., 2013. Hepatitis-C-virus-like internal ribosome entry sites displace eIF3 to gain access to the 40 S subunit. Nature 503, 539-543.

Hellen, C.U., de Breyne, S., 2007. A distinct group of hepacivirus/pestivirus-like internal ribosomal entry sites in members of diverse picornavirus genera: evidence for modular exchange of functional noncoding RNA elements by recombination. J. Virol. 81, 5850-5863.

Hinton, T.M., Crabb, B.S., 2001. The novel picornavirus Equine rhinitis B virus contains a strong type II internal ribosomal entry site which functions similarly to that of Encephalomyocarditis virus. J. Gen. Virol. 82, 2257-2269.

Hinton, T.M., Li, F., Crabb, B.S., 2000. Internal ribosomal entry site-mediated translation initiation in equine rhinitis A virus: similarities to and differences from that of foot-and-mouth disease virus. J. Virol. 74, 11708-11716.

Hoffman, M.A., Palmenberg, A.C., 1996. Revertant analysis of J-K mutations in the encephalomyocarditis virus internal ribosomal entry site detects an altered leader protein. J. Virol. 70, 6425-6430.

Hollister, J.R., Vagnozzi, A., Knowles, N.J., Rieder, E., 2008. Molecular and phylogenetic analyses of bovine rhinovirus type 2 shows it is closely related to foot-and-mouth disease virus. Virology 373, 411-425.

Honda, M., Ping, L.H., Rijnbrand, R.C., Amphlett, E., Clarke, B., Rowlands, D., Lemon, S.M., 1996. Structural requirements for initiation of translation by internal ribosome entry within genome-length hepatitis C virus RNA. Virology 222, 31-42.

Huang, P.N., Lin, J.Y., Locker, N., Kung, Y.A., Hung, C.T., Huang, H.I., Li, M.L., Shih, S.R., 2011. Far upstream element binding protein 1 binds the internal ribosomal entry site of enterovirus 71 and enhances viral translation and viral growth. Nucleic Acids Res. 39, 9633-9648.

Hunt, S.L., Hsuan, J.J., Totty, N., Jackson, R.J., 1999. unr, a cellular cytoplasmic RNAbinding protein with five cold-shock domains, is required for internal initiation of translation of human rhinovirus RNA. Genes Dev. 13, 437-448.

Jang, S.K., Krausslich, H.G., Nicklin, M.J., Duke, G.M., Palmenberg, A.C., Wimmer, E., 1988. A segment of the $5^{\prime}$ nontranslated region of encephalomyocarditis virus RNA directs internal entry of ribosomes during in vitro translation. J. Virol. 62, 2636-2643.

Jang, S.K., Wimmer, E., 1990. Cap-independent translation of encephalomyocarditis virus RNA: structural elements of the internal ribosomal entry site and involvement of a cellular 57-kD RNA-binding protein. Genes Dev. 4, 1560-1572.

Jung, S., Schlick, T., 2013. Candidate RNA structures for domain 3 of the footand-mouth-disease virus internal ribosome entry site. Nucleic Acids Res. 41 $1483-1495$

Jung, S., Schlick, T., 2014. Interconversion between parallel and antiparallel conformations of a 4H RNA junction in domain 3 of foot-and-mouth disease virus IRES captured by dynamics simulations. Biophys. J. 106, 447-458.

Kafasla, P., Morgner, N., Poyry, T.A., Curry, S., Robinson, C.V., Jackson, R.J., 2009. Polypyrimidine tract binding protein stabilizes the encephalomyocarditis virus
IRES structure via binding multiple sites in a unique orientation. Mol. Cell 34 556-568.

Kaku, Y., Chard, L.S., Inoue, T., Belsham, G.J., 2002. Unique characteristics of a picornavirus internal ribosome entry site from the porcine teschovirus- 1 talfan. J. Virol. 76, 11721-11728.

Kaminski, A., Belsham, G.J., Jackson, R.J., 1994. Translation of encephalomyocarditis virus RNA: parameters influencing the selection of the internal initiation site. EMBO J. 13, 1673-1681.

Kanda, T., Gauss-Muller, V., Cordes, S., Tamura, R., Okitsu, K., Shuang, W. Nakamoto, S., Fujiwara, K., Imazeki, F., Yokosuka, O., 2010. Hepatitis A virus (HAV) proteinase $3 \mathrm{C}$ inhibits HAV IRES-dependent translation and cleaves the polypyrimidine tract-binding protein. J. Viral Hepat. 17, 618-623.

Kim, Y.K., Jang, S.K., 1999. La protein is required for efficient translation driven by encephalomyocarditis virus internal ribosomal entry site. J. Gen. Virol. 80, 3159-3166.

King, J., Shammas, C., Nareen, M., Lelli, M., Ramesh, V., 2013. NMR characterisation of a highly conserved secondary structural RNA motif of Halobacterium halobium 23S rRNA. Org. Biomol. Chem. 11, 3382-3392.

Kolupaeva, V.G., Pestova, T.V., Hellen, C.U., Shatsky, I.N., 1998. Translation eukaryotic initiation factor $4 \mathrm{G}$ recognizes a specific structural element within the internal ribosome entry site of encephalomyocarditis virus RNA. J. Biol. Chem. 273, 18599-18604.

Kuhn, R., Luz, N., Beck, E., 1990. Functional analysis of the internal translation initiation site of foot-and-mouth disease virus. J. Virol. 64, 4625-4631.

Lamphear, B.J., Yan, R., Yang, F., Waters, D., Liebig, H.D., Klump, H., Kuechler, E., Skern, T., Rhoads, R.E., 1993. Mapping the cleavage site in protein synthesis initiation factor eIF-4 gamma of the 2A proteases from human Coxsackievirus and rhinovirus. J. Biol. Chem. 268, 19200-19203.

Lawrence, P., Schafer, E.A., Rieder, E., 2012. The nuclear protein Sam68 is cleaved by the FMDV $3 C$ protease redistributing Sam68 to the cytoplasm during FMDV infection of host cells. Virology 425, 40-52.

Levengood, J.D., Tolbert, M., Li, M.L., Tolbert, B.S., 2013. High-affinity interaction of hnRNP A1 with conserved RNA structural elements is required for translation and replication of enterovirus 71. RNA Biol. 10, 1136-1145.

Li, W., Ross-Smith, N., Proud, C.G., Belsham, G.J., 2001. Cleavage of translation initiation factor 4AI (eIF4AI) but not eIF4AII by foot-and-mouth disease virus 3C protease: identification of the eIF4AI cleavage site. FEBS Lett. 507, 1-5.

Liao, Q., Zheng, L., Yuan, Y., Shi, J., Zhang, D., 2014. Genomic characterization of a novel picornavirus in Pekin ducks. Vet. Microbiol. 172, 78-91.

Lin, J.Y., Li, M.L., Huang, P.N., Chien, K.Y., Horng, J.T., Shih, S.R., 2008. Heterogeneous nuclear ribonuclear protein $\mathrm{K}$ interacts with the enterovirus $715^{\prime}$ untranslated region and participates in virus replication. J. Gen. Virol. 89, 2540-2549.

Lin, J.Y., Li, M.L., Shih, S.R., 2009a. Far upstream element binding protein 2 interacts with enterovirus 71 internal ribosomal entry site and negatively regulates vira translation. Nucleic Acids Res. 37, 47-59.

Lin, J.Y., Shih, S.R., Pan, M., Li, C., Lue, C.F., Stollar, V., Li, M.L., 2009b. hnRNP A1 interacts with the $5^{\prime}$ untranslated regions of enterovirus 71 and Sindbis virus RNA and is required for viral replication. J. Virol. 83, 6106-6114.

Lopez de Quinto, S., Lafuente, E., Martinez-Salas, E., 2001. IRES interaction with translation initiation factors: functional characterization of novel RNA contacts with eIF3, eIF4B, and eIF4GII. RNA 7, 1213-1226.

Lopez de Quinto, S., Martinez-Salas, E., 1997. Conserved structural motifs located in distal loops of aphthovirus internal ribosome entry site domain 3 are required for internal initiation of translation. J. Virol. 71, 4171-4175

Lopez de Quinto, S., Martinez-Salas, E., 1999. Involvement of the aphthovirus RNA region located between the two functional AUGs in start codon selection. Virology 255, 324-336.

Lopez de Quinto, S., Martinez-Salas, E., 2000. Interaction of the eIF4G initiation facto with the aphthovirus IRES is essential for internal translation initiation in vivo. RNA 6, 1380-1392.

Lopez de Quinto, S., Saiz, M., de la Morena, D., Sobrino, F., Martinez-Salas, E., 2002. IRES-driven translation is stimulated separately by the FMDV 3'-NCR and poly(A) sequences. Nucleic Acids Res. 30, 4398-4405.

Lopez-Lastra, M., Ramdohr, P., Letelier, A., Vallejos, M., Vera-Otarola, J., ValienteEcheverria, F., 2010. Translation initiation of viral mRNAs. Rev. Med. Virol. 20 177-195.

Lozano, G., Fernandez, N., Martinez-Salas, E., 2014. Magnesium-dependent folding of a picornavirus IRES element modulates RNA conformation and eIF4G interaction. FEBS J. 281, 3685-3700.

Lunde, B.M., Moore, C., Varani, G., 2007. RNA-binding proteins: modular design for efficient function. Nat. Rev. Mol. Cell Biol. 8, 479-490.

Luz, N., Beck, E., 1991. Interaction of a cellular 57-kilodalton protein with the internal translation initiation site of foot-and-mouth disease virus. J. Virol. 65 6486-6494.

Malnou, C.E., Poyry, T.A., Jackson, R.J., Kean, K.M., 2002. Poliovirus internal ribosome entry segment structure alterations that specifically affect function in neurona cells: molecular genetic analysis. J. Virol. 76, 10617-10626.

Marcotrigiano, J., Lomakin, I.B., Sonenberg, N., Pestova, T.V., Hellen, C.U., Burley, S.K., 2001. A conserved HEAT domain within eIF4G directs assembly of the translation initiation machinery. Mol. Cell 7, 193-203.

Martinez-Salas, E., 2008. The impact of RNA structure on picornavirus IRES activity. Trends Microbiol. 16, 230-237.

Martinez-Salas, E., Pacheco, A., Serrano, P., Fernandez, N., 2008. New insights into internal ribosome entry site elements relevant for viral gene expression. J. Gen. Virol. 89, 611-626. 
Martinez-Salas, E., Pineiro, D., Fernandez, N., 2012. Alternative mechanisms to initiate translation in eukaryotic mRNAs. Comp. Funct. Genomics 2012, 391546.

Martinez-Salas, E., Regalado, M.P., Domingo, E., 1996. Identification of an essential region for internal initiation of translation in the aphthovirus internal ribosome entry site and implications for viral evolution. J. Virol. 70, 992-998.

Martinez-Salas, E., Saiz, J.C., Davila, M., Belsham, G.J., Domingo, E., 1993. A single nucleotide substitution in the internal ribosome entry site of foot-and-mouth disease virus leads to enhanced cap-independent translation in vivo. J. Virol. 67, 3748-3755

Mason, P.W., Bezborodova, S.V., Henry, T.M., 2002. Identification and characterization of a cis-acting replication element (cre) adjacent to the internal ribosome entry site of foot-and-mouth disease virus. J. Virol. 76, 9686-9694.

Melchers, W.J., Hoenderop, J.G., Bruins Slot, H.J., Pleij, C.W., Pilipenko, E.V., Agol, V.I., Galama, J.M., 1997. Kissing of the two predominant hairpin loops in the coxsackie B virus $3^{\prime}$ untranslated region is the essential structural feature of the origin of replication required for negative-strand RNA synthesis. J. Virol. 71, 686-696.

Merrill, M.K., Gromeier, M., 2006. The double-stranded RNA binding protein 76:NF45 heterodimer inhibits translation initiation at the rhinovirus type 2 internal ribosome entry site. J. Virol. 80, 6936-6942.

Meyer, K., Petersen, A., Niepmann, M., Beck, E., 1995. Interaction of eukaryotic initiation factor eIF-4B with a picornavirus internal translation initiation site. J. Virol. 69, 2819-2824.

Monie, T.P., Perrin, A.J., Birtley, J.R., Sweeney, T.R., Karakasiliotis, I., Chaudhry, Y., Roberts, L.O., Matthews, S., Goodfellow, I.G., Curry, S., 2007. Structural insights into the transcriptional and translational roles of Ebp1. EMBO J. 26, 3936-3944.

Mukherjee, A., Morosky, S.A., Delorme-Axford, E., Dybdahl-Sissoko, N., Oberste, M.S., Wang, T., Coyne, C.B., 2011. The coxsackievirus B 3C protease cleaves MAVS and TRIF to attenuate host type I interferon and apoptotic signaling. PLoS Pathog. 7 , e1001311.

Nateri, A.S., Hughes, P.J., Stanway, G., 2000. In vivo and in vitro identification of structural and sequence elements of the human parechovirus $5^{\prime}$ untranslated region required for internal initiation. J. Virol. 74, 6269-6277.

Nicholson, B.L., White, K.A., 2014. Functional long-range RNA-RNA interactions in positive-strand RNA viruses. Nat. Rev. Microbiol. 12, 493-504.

Ohlmann, T., Rau, M., Pain, V.M., Morley, S.J., 1996. The C-terminal domain of eukaryotic protein synthesis initiation factor (eIF) $4 \mathrm{G}$ is sufficient to support cap-independent translation in the absence of eIF4E. EMBO J. 15, 1371-1382.

Pacheco, A., Lopez de Quinto, S., Ramajo, J., Fernandez, N., Martinez-Salas, E., 2009. A novel role for Gemin5 in mRNA translation. Nucleic Acids Res. 37, 582-590.

Pacheco, A., Reigadas, S., Martinez-Salas, E., 2008. Riboproteomic analysis of polypeptides interacting with the internal ribosome-entry site element of footand-mouth disease viral RNA. Proteomics 8, 4782-4790.

Pan, M., Yang, X., Zhou, L., Ge, X., Guo, X., Liu, J., Zhang, D., Yang, H., 2012. Duck Hepatitis A virus possesses a distinct type IV internal ribosome entry site element of picornavirus. J. Virol. 86, 1129-1144

Park, N., Skern, T., Gustin, K.E., 2010. Specific cleavage of the nuclear pore complex protein Nup62 by a viral protease. J. Biol. Chem. 285, 28796-28805.

Parks, G.D., Baker, J.C., Palmenberg, A.C., 1989. Proteolytic cleavage of encephalomyocarditis virus capsid region substrates by precursors to the 3 C enzyme. J. Virol. 63, 1054-1058.

Parsyan, A., Svitkin, Y., Shahbazian, D., Gkogkas, C., Lasko, P., Merrick, W.C., Sonenberg, N., 2011. mRNA helicases: the tacticians of translational control. Nat. Rev. Mol. Cell Biol. 12, 235-245

Pelletier, J., Flynn, M.E., Kaplan, G., Racaniello, V., Sonenberg, N., 1988. Mutational analysis of upstream AUG codons of poliovirus RNA. J. Virol. 62, 4486-4492.

Pelletier, J., Sonenberg, N., 1988. Internal initiation of translation of eukaryotic mRNA directed by a sequence derived from poliovirus RNA. Nature 334, 320-325.

Pestova, T.V., Shatsky, I.N., Hellen, C.U., 1996. Functional dissection of eukaryotic initiation factor $4 \mathrm{~F}$ : the $4 \mathrm{~A}$ subunit and the central domain of the $4 \mathrm{G}$ subunit are sufficient to mediate internal entry of $43 \mathrm{~S}$ preinitiation complexes. Mol. Cell. Biol. 16, 6870-6878

Phelan, M., Banks, R.J., Conn, G., Ramesh, V., 2004. NMR studies of the structure and $\mathrm{Mg} 2+$ binding properties of a conserved RNA motif of EMCV picornavirus IRES element. Nucleic Acids Res. 32, 4715-4724

Pilipenko, E.V., Gmyl, A.P., Maslova, S.V., Belov, G.A., Sinyakov, A.N., Huang, M., Brown, T.D., Agol, V.I., 1994. Starting window, a distinct element in the capindependent internal initiation of translation on picornaviral RNA. J. Mol. Biol. 241, 398-414

Pilipenko, E.V., Gmyl, A.P., Maslova, S.V., Svitkin, Y.V., Sinyakov, A.N., Agol, V.I., 1992. Prokaryotic-like cis elements in the cap-independent internal initiation of translation on picornavirus RNA. Cell 68, 119-131

Pilipenko, E.V., Pestova, T.V., Kolupaeva, V.G., Khitrina, E.V., Poperechnaya, A.N., Agol, V.I., Hellen, C.U., 2000. A cell cycle-dependent protein serves as a templatespecific translation initiation factor. Genes Dev. 14, 2028-2045.

Pilipenko, E.V., Poperechny, K.V., Maslova, S.V., Melchers, W.J., Slot, H.J., Agol, V.I., 1996. Cis-element, oriR, involved in the initiation of (-) strand poliovirus RNA: a quasi-globular multi-domain RNA structure maintained by tertiary ('kissing') interactions. EMBO J. 15, 5428-5436.

Pilipenko, E.V., Viktorova, E.G., Guest, S.T., Agol, V.I., Roos, R.P., 2001. Cell-specific proteins regulate viral RNA translation and virus-induced disease. EMBO J. 20, 6899-6908

Pineiro, D., Fernandez, N., Ramajo, J., Martinez-Salas, E., 2013. Gemin5 promotes IRES interaction and translation control through its C-terminal region. Nucleic Acids Res. 41, 1017-1028.
Pineiro, D., Ramajo, J., Bradrick, S.S., Martinez-Salas, E., 2012. Gemin5 proteolysis reveals a novel motif to identify L protease targets. Nucleic Acids Res. 40, 4942-4953.

Pisarev, A.V., Chard, L.S., Kaku, Y., Johns, H.L., Shatsky, I.N., Belsham, G.J., 2004. Functional and structural similarities between the internal ribosome entry sites of hepatitis C virus and porcine teschovirus, a picornavirus. J. Virol. 78, 4487-4497.

Plank, T.D., Kieft, J.S., 2012. The structures of nonprotein-coding RNAs that drive internal ribosome entry site function. Wiley Interdiscip. Rev. RNA 3, 195-212.

Ramos, R., Martinez-Salas, E., 1999. Long-range RNA interactions between structural domains of the aphthovirus internal ribosome entry site (IRES). RNA 5 1374-1383.

Ray, P.S., Das, S., 2002. La autoantigen is required for the internal ribosome entry site-mediated translation of Coxsackievirus B3 RNA. Nucleic Acids Res. 30 4500-4508

Robertson, M.E., Seamons, R.A., Belsham, G.J., 1999. A selection system for functiona internal ribosome entry site (IRES) elements: analysis of the requirement for a conserved GNRA tetraloop in the encephalomyocarditis virus IRES. RNA 5 1167-1179.

Rodriguez Pulido, M., Serrano, P., Saiz, M., Martinez-Salas, E., 2007. Foot-and-mouth disease virus infection induces proteolytic cleavage of PTB, eIF3a,b, and PABP RNA-binding proteins. Virology 364, 466-474.

Romero-Lopez, C., Barroso-Deljesus, A., Garcia-Sacristan, A., Briones, C., BerzalHerranz, A., 2014. End-to-end crosstalk within the hepatitis C virus genome mediates the conformational switch of the $3^{\prime} \mathrm{X}$-tail region. Nucleic Acids Res. 42 567-582.

Rozovics, J.M., Chase, A.J., Cathcart, A.L., Chou, W., Gershon, P.D., Palusa, S., Wilusz, J., Semler, B.L., 2012. Picornavirus modification of a host mRNA decay protein. MBio 3, e00431-00412.

Saiz, M., Gomez, S., Martinez-Salas, E., Sobrino, F., 2001. Deletion or substitution of the aphthovirus 3' NCR abrogates infectivity and virus replication. J. Gen. Virol. 82, 93-101.

Schultz, D.E., Honda, M., Whetter, L.E., McKnight, K.L., Lemon, S.M., 1996. Mutations within the 5' nontranslated RNA of cell culture-adapted hepatitis A virus which enhance cap-independent translation in cultured African green monkey kidney cells. J. Virol. 70, 1041-1049.

Sean, P., Nguyen, J.H., Semler, B.L., 2009. Altered interactions between stem-loop IV within the 5' noncoding region of coxsackievirus RNA and poly(rC) binding protein 2: effects on IRES-mediated translation and viral infectivity. Virology $389,45-58$.

Seipelt, J., Guarne, A., Bergmann, E., James, M., Sommergruber, W., Fita, I., Skern, T. 1999. The structures of picornaviral proteinases. Virus Res. 62, 159-168.

Serrano, P., Gomez, J., Martinez-Salas, E., 2007. Characterization of a cyanobacterial RNase P ribozyme recognition motif in the IRES of foot-and-mouth disease virus reveals a unique structural element. RNA 13, 849-859.

Serrano, P., Pulido, M.R., Saiz, M., Martinez-Salas, E., 2006. The 3' end of the footand-mouth disease virus genome establishes two distinct long-range RNA-RNA interactions with the 5' end region. J. Gen. Virol. 87, 3013-3022.

Serrano, P., Ramajo, J., Martinez-Salas, E., 2009. Rescue of internal initiation of translation by RNA complementation provides evidence for a distribution of functions between individual IRES domains. Virology 388, 221-229.

Shiroki, K., Isoyama, T., Kuge, S., Ishii, T., Ohmi, S., Hata, S., Suzuki, K., Takasaki, Y. Nomoto, A., 1999. Intracellular redistribution of truncated La protein produced by poliovirus 3Cpro-mediated cleavage. J. Virol. 73, 2193-2200.

Simon, A.E., Miller, W.A., 2013. 3' cap-independent translation enhancers of plant viruses. Annu. Rev. Microbiol. 67, 21-42

Skern, T., Sommergruber, W., Auer, H., Volkmann, P., Zorn, M., Liebig, H.D., Fessl, F., Blaas, D., Kuechler, E., 1991. Substrate requirements of a human rhinoviral 2A proteinase. Virology 181, 46-54.

Sonenberg, N., Hinnebusch, A.G., 2009. Regulation of translation initiation in eukaryotes: mechanisms and biological targets. Cell 136, 731-745.

Steinberger, J., Grishkovskaya, I., Cencic, R., Juliano, L., Juliano, M.A., Skern, T., 2014. Foot-and-mouth disease virus leader proteinase: structural insights into the mechanism of intermolecular cleavage. Virology 468-470C, 397-408.

Sun, C., Querol-Audi, J., Mortimer, S.A., Arias-Palomo, E., Doudna, J.A., Nogales, E., Cate, J.H., 2013. Two RNA-binding motifs in eIF3 direct HCV IRES-dependent translation. Nucleic Acids Res. 41, 7512-7521.

Sweeney, T.R., Abaeva, I.S., Pestova, T.V., Hellen, C.U., 2014. The mechanism of translation initiation on Type 1 picornavirus IRESs. EMBO J. 33, 76-92.

Sweeney, T.R., Dhote, V., Yu, Y., Hellen, C.U., 2012. A distinct class of internal ribosomal entry site in members of the Kobuvirus and proposed Salivirus and Paraturdivirus genera of the Picornaviridae. J. Virol. 86, 1468-1486.

Sweeney, T.R., Roque-Rosell, N., Birtley, J.R., Leatherbarrow, R.J., Curry, S., 2007. Structural and mutagenic analysis of foot-and-mouth disease virus 3 C protease reveals the role of the beta-ribbon in proteolysis. J. Virol. 81, 115-124.

Todd, S., Towner, J.S., Semler, B.L., 1997. Translation and replication properties of the human rhinovirus genome in vivo and in vitro. Virology 229, 90-97.

Toyoda, H., Franco, D., Fujita, K., Paul, A.V., Wimmer, E., 2007. Replication of Poliovirus requires binding of the poly $(\mathrm{rC})$ binding protein to the cloverleaf as well as to the adjacent C-rich spacer sequence between the cloverleaf and the internal ribosomal entry site. J. Virol. 81, 10017-10028.

Toyoda, H., Nicklin, M.J., Murray, M.G., Anderson, C.W., Dunn, J.J., Studier, F.W., Wimmer, E., 1986. A second virus-encoded proteinase involved in proteolytic processing of poliovirus polyprotein. Cell 45, 761-770.

Trono, D., Pelletier, J., Sonenberg, N., Baltimore, D., 1988. Translation in mammalian cells of a gene linked to the poliovirus $5^{\prime}$ noncoding region. Science 241 $445-448$. 
Tsukiyama-Kohara, K., Iizuka, N., Kohara, M., Nomoto, A., 1992. Internal ribosome entry site within hepatitis C virus RNA. J. Virol. 66, 1476-1483.

Vallejos, M., Ramdohr, P., Valiente-Echeverria, F., Tapia, K., Rodriguez, F.E., Lowy, F., Huidobro-Toro, J.P., Dangerfield, J.A., Lopez-Lastra, M., 2010. The 5'-untranslated region of the mouse mammary tumor virus mRNA exhibits cap-independent translation initiation. Nucleic Acids Res. 38, 618-632.

Verma, B., Bhattacharyya, S., Das, S., 2010. Polypyrimidine tract-binding protein interacts with coxsackievirus B3 RNA and influences its translation. J. Gen. Virol. 91, 1245-1255.

Waggoner, S., Sarnow, P., 1998. Viral ribonucleoprotein complex formation and nucleolar-cytoplasmic relocalization of nucleolin in poliovirus-infected cells. J. Virol. 72, 6699-6709.

Walsh, D., Mohr, I., 2011. Viral subversion of the host protein synthesis machinery. Nat. Rev. Microbiol. 9, 860-875.

Walter, B.L., Nguyen, J.H., Ehrenfeld, E., Semler, B.L., 1999. Differential utilization of poly $(\mathrm{rC})$ binding protein 2 in translation directed by picornavirus IRES elements. RNA 5, 1570-1585.

Wang, J., Bakkers, J.M., Galama, J.M., Bruins Slot, H.J., Pilipenko, E.V.,Agol, V.I., Melchers, W.J., 1999. Structural requirements of the higher order RNA kissing element in the enteroviral 3'UTR. Nucleic Acids Res. 27, 485-490.

Watters, K., Palmenberg, A.C., 2011. Differential processing of nuclear pore complex proteins by rhinovirus $2 A$ proteases from different species and serotypes. J. Virol. 85, 10874-10883.
Weng, K.F., Li, M.L., Hung, C.T., Shih, S.R., 2009. Enterovirus 71 3C protease cleaves a novel target CstF-64 and inhibits cellular polyadenylation. PLoS Pathog 5, e1000593.

White, J.P., Cardenas, A.M., Marissen, W.E., Lloyd, R.E., 2007. Inhibition of cytoplasmic mRNA stress granule formation by a viral proteinase. Cell Host Microbe 2, 295-305.

Willcocks, M.M., Locker, N., Gomwalk, Z., Royall, E., Bakhshesh, M., Belsham, G.J., Idamakanti, N., Burroughs, K.D., Reddy, P.S., Hallenbeck, P.L., Roberts, L.O., 2011. Structural features of the Seneca Valley virus internal ribosome entry site (IRES) element: a picornavirus with a pestivirus-like IRES. J. Virol. 85, 4452-4461.

Wilson, J.E., Pestova, T.V., Hellen, C.U., Sarnow, P., 2000. Initiation of protein synthesis from the A site of the ribosome. Cell 102, 511-520.

Woo, P.C., Lau, S.K., Choi, G.K., Huang, Y., Teng, J.L., Tsoi, H.W., Tse, H., Yeung, M.L., Chan, K.H., Jin, D.Y., Yuen, K.Y., 2012. Natural occurrence and characterization of two internal ribosome entry site elements in a novel virus, canine picodicistrovirus, in the picornavirus-like superfamily. J. Virol. 86, 2797-2808.

Yu, Y., Abaeva, I.S., Marintchev, A., Pestova, T.V., Hellen, C.U., 2011a. Common conformational changes induced in type 2 picornavirus IRESs by cognate trans-acting factors. Nucleic Acids Res. 39, 4851-4865.

Yu, Y., Sweeney, T.R., Kafasla, P., Jackson, R.J., Pestova, T.V., Hellen, C.U., 2011b. The mechanism of translation initiation on Aichivirus RNA mediated by a novel type of picornavirus IRES. EMBO J. 30, 4423-4436. 